\title{
Liver proteome alterations in psychologically distressed rats and a nootropic drug
}

\author{
Raquel González-Fernández ${ }^{\text {Corresp., } 1}{ }^{\text {, Mariana Grigoruță }}{ }^{1}$, Sarahi Chávez-Martínez ${ }^{1}$, Eliel Ruiz-May ${ }^{2}$, José Miguel \\ Elizalde-Contreras ${ }^{2}$, José Valero-Galván ${ }^{1}$, Alejandro Martínez-Martínez ${ }^{1}$ \\ ${ }^{1}$ Departamento de Ciencias Químico Biológicas, Instituto de Ciencias Biomédicas, Universidad Autónoma de Ciudad Juárez, Ciudad Juárez, Chihuahua, \\ Mexico \\ ${ }^{2}$ Red de Estudios Moleculares Avanzados, Instituto de Ecología A.C. (INECOL), Xalapa, Veracruz, México \\ Corresponding Author: Raquel González-Fernández \\ Email address: raquel.gonzalez@uacj.mx
}

Background. Chronic psychological distress is considered today a pandemic due to the modern lifestyle and has been associated with various neurodegenerative, autoimmune, or systemic inflammation-related diseases. Stress is closely related to liver disease exacerbation through the high activity of the endocrine and autonomic nervous systems, and the connection between the development of these pathologies and the physiological effects induced by oxidative stress is not yet completely understood. The use of nootropics, as the cognitive enhancer and antioxidant piracetam, is attractive to repair the oxidative damage. A proteomic approach provides the possibility to obtain an in-depth comprehension of the affected cellular processes and the possible consequences for the body. Therefore, we considered to describe the effect of distress and piracetam on the liver proteome.

Methods. We used a murine model of psychological stress by predatory odor as a distress paradigm. Female Sprague-Dawley rats were distributed into four experimental groups ( $n=6-7 /$ group) and were exposed or not to the stressor for five days and treated or not with piracetam $(600 \mathrm{mg} / \mathrm{kg})$ for six days. We evaluated the liver proteome by one-dimensional sodium dodecyl sulfate-polyacrylamide gel electrophoresis (1D-SDS-PAGE) followed by liquid chromatography-tandem mass spectrometry (GeLCMS/MS). Besides, we analyzed the activity of liver antioxidant enzymes, the biochemical parameters in plasma and rat behavior.

Results. Our results showed that distress altered a wide range of proteins involved in amino acids metabolism, glucose, and fatty acid mobilization and degradation on the way to produce energy, protein folding, trafficking and degradation, redox metabolism, and its implications in the development of the non-alcoholic fatty liver disease (NAFLD). Piracetam reverted the changes in metabolism caused by distress exposure, and, under physiological conditions, it increased catabolism rate directed towards energy production. These results confirm the possible relationship between chronic psychological stress and the progression of NAFLD, as well as we newly evidenced the controversial beneficial effects of piracetam. Finally, we propose new distress biomarkers in the liver as the protein DJ-1 (PARK7), glutathione peroxidase 1 (GPX) peroxiredoxin-5 (PRDX5), glutaredoxin 5 (GLRX5), and thioredoxin reductase 1 (TXNDR1), and in plasma as biochemical parameters related to kidney function such as urea and blood urea nitrogen (BUN) levels. 


\section{Liver proteome alterations in psychologically distressed rats}

\section{2 and a nootropic drug}

3 Raquel González-Fernández ${ }^{1}$, Mariana Grigoruţă ${ }^{1}$, Sarahí Chávez-Martínez ${ }^{1}$, Eliel Ruiz-May², José Miguel

4 Elizalde-Contreras ${ }^{2}$, José Valero-Galván ${ }^{1}$, Alejandro Martínez-Martínez ${ }^{1}$

5

$6 \quad{ }^{1}$ Departamento de Ciencias Químico Biológicas, Instituto de Ciencias Biomédicas, Universidad

7 Autónoma de Ciudad Juárez, Anillo envolvente Pronaf y Estocolmo s/n, CP 32310, Ciudad Juárez,

8 Chihuahua, México.

92 Red de Estudios Moleculares Avanzados, Instituto de Ecología A.C. (INECOL), Carretera Antigua a

10 Coatepec No. 351, Congregación el Haya, CP 91070, Xalapa, Veracruz, México.

11

12 Corresponding Author:

13 Raquel González-Fernández

14 Departamento de Ciencias Químico Biológicas, Instituto de Ciencias Biomédicas, Universidad Autónoma 15 de Ciudad Juárez, Anillo envolvente Pronaf y Estocolmo s/n, CP 32310, Ciudad Juárez, México.

Email address: raquel.gonzalez@uacj.mx 
17 Liver proteome alterations in psychologically distressed rats and a nootropic drug

\author{
Raquel González-Fernández ${ }^{1}$, Mariana Grigoruţă ${ }^{1}$, Sarahí Chávez-Martínez ${ }^{1}$, Eliel Ruiz-May ${ }^{2}$, \\ José Miguel Elizalde-Contreras ${ }^{2}$, José Valero-Galván ${ }^{1}$, Alejandro Martínez-Martínez ${ }^{1}$ \\ ${ }^{1}$ Departamento de Ciencias Químico Biológicas, Instituto de Ciencias Biomédicas, Universidad \\ Autónoma de Ciudad Juárez, Anillo envolvente Pronaf y Estocolmo s/n, CP 32310, Ciudad \\ Juárez, Chihuahua, México. \\ ${ }^{2}$ Red de Estudios Moleculares Avanzados, Instituto de Ecología A.C. (INECOL), Carretera \\ Antigua a Coatepec No. 351, Congregación el Haya, CP 91070, Xalapa, Veracruz, México. \\ Corresponding Author: \\ Raquel González-Fernández \\ Departamento de Ciencias Químico Biológicas, Instituto de Ciencias Biomédicas, Universidad \\ Autónoma de Ciudad Juárez, Anillo envolvente Pronaf y Estocolmo s/n, CP 32310, Ciudad \\ Juárez, México. \\ Email address: raquel.gonzalez@uacj.mx
}

\title{
Abstract
}

Background. Psychological distress is considered today a pandemic due to the modern lifestyle and has been associated with various neurodegenerative, autoimmune, or systemic inflammationrelated diseases. The physiological response induced by distress is closely related to liver disease exacerbation through the high activity of the endocrine and autonomic nervous systems, and the connection between the development of these pathologies and the physiological effects induced by oxidative stress is not yet completely understood. The use of nootropics, as the cognitive enhancer and antioxidant piracetam, is attractive to repair the oxidative damage. A proteomic approach provides the possibility to obtain an in-depth comprehension of the affected cellular processes and the possible consequences for the body. Therefore, we considered to describe the effect of distress and piracetam on the liver proteome.

Methods. We used a murine model of chronic psychological stress by predatory odor as a distress paradigm. Female Sprague-Dawley rats were distributed into four experimental groups ( $n=6-7 /$ group) and were exposed or not to the stressor for five days and treated or not with piracetam $(600 \mathrm{mg} / \mathrm{kg})$ for six days. We evaluated the liver proteome by one-dimensional sodium dodecyl sulfate-polyacrylamide gel electrophoresis (1D-SDS-PAGE) followed by liquid chromatography-tandem mass spectrometry (GeLC-MS/MS). Besides, we analyzed the activity of liver antioxidant enzymes, the biochemical parameters in plasma and rat behavior.

Results. Our results showed that distress altered a wide range of proteins involved in amino acids metabolism, glucose, and fatty acid mobilization and degradation on the way to produce energy, protein folding, trafficking and degradation, redox metabolism, and its implications in the development of the non-alcoholic fatty liver disease (NAFLD). Piracetam reverted the changes in metabolism caused by distress exposure, and, under physiological conditions, it 
59

60

61

62

63

64

65

66

67

68

69

70

71

72

73

74

75

76

77

78

79

80

81

82

83

84

85

86

87

88

89

90

91

92

93

94

95

96

97

98

99

100

101

102

103

104

increased catabolism rate directed towards energy production. These results confirm the possible relationship between chronic psychological stress and the progression of NAFLD, as well as we newly evidenced the controversial beneficial effects of piracetam. Finally, we propose new protein targets for distress studies in the liver as the protein DJ-1 (PARK7), glutathione peroxidase 1 (GPX), peroxiredoxin-5 (PRDX5), glutaredoxin 5 (GLRX5), thioredoxin reductase 1 (TXNDR1), and in plasma the biochemical parameters related to kidney function such as urea and blood urea nitrogen (BUN).

\section{Introduction}

Psychological stress is considered a critical public health problem due to the modern lifestyle. When this tension is prolonged over time, it induces an emotional response referred to as distress characterized by a negative body response (Westley et al., 2021). This emotional condition causes physiological changes that involve both nervous and immune systems inducing systemic inflammation (Furman et al., 2019) that leads to mental illnesses, like anxiety, fear, and depression (Canteras, Pavesi, and Carobrez 2015). Nowadays, the connection between the mind and the body is well proved, which shows that physical wellness is closely bound to mental health. Thus, a dose-response relationship has been found between psychological distress and chronic diseases, such as cardiovascular diseases, hepatic disorders, and cancer (Russ et al., 2015; Yang et al., 2020).

The liver has an essential role in the body due to its function in the storage of glycogen, synthesis of plasma proteins, elimination of erythrocytes, detoxification, among all. Also, this organ has anabolic activity providing energy-rich compounds, such as glucose and lipids, essential for the adaptive response of body to distress (Duda et al., 2016). Increasing evidence indicates that psychological distress alters liver homeostasis. Chronic release of a high amount of glucocorticoids and catecholamines activates catabolic pathways in the liver and induces changes in the local immune response, which is closely related to the development or exacerbation of inflammatory liver diseases (Depke et al. 2009; Srivastava and Boyer 2010). The impairment of the hepatic blood flow by the chronic liberation of corticotropin-releasing factor is also considered a mechanism through which emotional stimuli affect the liver (Chida, Sudo \& Kubo, 2005). Thus, in previous studies, psychological distress induces changes in hepatic gene expression related to cell growth, proliferation and survival, local inflammatory response, and protein and lipid metabolism, and stimulates gluconeogenesis, hypercholesterolemia, and hepatic steatosis development (Adachi, Kawamura \& Takemoto, 1993; Depke et al., 2008, 2009; Zhao et al., 2013). Furthermore, both physical and psychological distress induced oxidative stress, by altering antioxidant enzyme activity and glutathione level in hepatic tissue (Jafari et al., 2014). The hypothalamic-pituitary-adrenal axis modulates the neurobehavioral and physiological responses to stress, triggering the release of reactive oxygen species (ROS) that cause oxidative damage to the DNA, proteins and lipids (Kinlein \& Karatsoreos, 2019). The oxidative stress generated in response to psychological distress is related to various diseases such as neurodegenerative diseases (Wadhwa \& Maurya, 2018), type 2 diabetes mellitus (Hackett \& Steptoe, 2017), autoimmune diseases (Sharif et al., 2018), cancer (Kruk et al., 2019), among all. Although it is assumed that there is a relationship between the physiological effects of oxidative stress and inflammation caused by psychological distress and the development of such diseases, it is still unclear how this connection occurs. Moreover, endocrine regulation and changes in hormone levels across the lifespan can affect the mechanisms and consequences of the distress response. An increased susceptibility to autoimmune and other non-viral liver diseases (Krok \& 
105 Koteish, 2010; Guy \& Peters, 2013) and depression and anxiety disorders (Hanamsagar \& Bilbo, 106 2016) was reported in women compared to men. However, female cyclical hormonal variations 107 are often a reason to exclude them in research studies.

108 In previous studies, we showed that distress induces alterations in the redox status and in the 109 bioenergetics in several brain regions like the amygdala, prefrontal cortex, and midbrain. Also, 110 we associated these changes with anxiety, motor dysfunction (Mejia-Carmona et al., 2015;

111 Grigoruţă et al., 2019), neuroinflammation and leukocyte recruitment in the area postrema

112 (Vargas-Caraveo, Pérez-Ishiwara \& Martínez-Martínez, 2015). Furthermore, this

113 neuroinflammation is associated with lipid peroxidation and protein denaturation, measured by

114 synchrotron radiation-based FTIR (SR- $\mu$ FTIR), in circulating lymphocytes from rats exposed to

115 predatory odor (Grigoruţă et al., 2018). Moreover, psychological distress reduced the

116 mitochondrial content in the midbrain and the rate of glycolysis and oxidative phosphorylation in

117 the prefrontal cortex and phenocopied some features of Parkinson's disease (PD)

118 neuropathology. Also, distress significantly changed the expression of the antioxidant enzymes

119 in the brain: it induced the increase of SOD2 expression in the prefrontal cortex and the decrease

120 of CAT level in the midbrain from male rats, and reduced SOD2 expression in the prefrontal

121 cortex and SOD1 and SOD2 levels in the striatum in female rats (Grigoruţă et al., 2019).

122 Research on pharmacological compounds able to repair the oxidative damage caused by

123 psychological stress is of great interest. The nootropics are known as "smart drugs" and stimulate memory and cognition. Piracetam was the first of these drugs to be described and, despite being a 2-oxo-1-pyrrolidine-acetamide, a derivate from gamma-aminobutyric acid (GABA), it showed opposite effects. It is commonly used as a neuronal enhancer because accumulated studies

127 showed that it mainly modulates cholinergic and glutamatergic neurotransmission (Malykh \&

128 Sadaie, 2010). In clinical practice, piracetam is used as adjuvant therapy, as it protects against brain damage and improves cognitive functions in epilepsy and ischemia, and recently his antiparkinsonian activity was reported (Gupta et al., 2014). It is well known that piracetam protects neuronal cells against oxidative stress (Verma et al., 2018), increases mitochondrial membrane fluidity and ATP production (Müller et al., 1997), and improves the mitochondrial membrane potential (Keil et al., 2006; Kurz et al., 2010), as well as the glucose uptake and utilization (Abdel-Salam et al., 2013; Pandey \& Garabadu, 2016), making this drug a metabolic enhancer and a neuroprotector. Thus, in animal and human studies, piracetam protected the brain against memory and cognitive function impairments induced by physical and chemical agents or by age (Kessler et al., 2000; Holinski et al., 2008; Gupta et al., 2009; Abdel-Salam et al., 2011; Kosta et al., 2011; Muley et al., 2013; Wang, Li \& Chen, 2016) and improved cognition and working memory in healthy volunteers (Alkuraishy et al., 2014). In a previous study, we also evidenced the anxiolytic effect and the protective role of this drug against lipid peroxidation in circulating mononuclear cells in rats subjected to psychological distress (Grigoruţă et al., 2018). However, there are few studies related to the effect of this drug on the liver. Piracetam had protective effects against the cytotoxicity of valproic acid in hepatocytes (Shrestha et al., 2014) but did not induce significant effects on oxidative stress markers from mice liver treated with cannabis extract and this drug (Abdel-Salam et al., 2013).

The analysis of liver response under anomalous conditions has traditionally been investigated through a reductionist vision. The development of technologies such as proteomics made holistic

149 Proteomic studies carried out in the liver from murine models exposed to psychological stress are 150 scarce, and the authors have mainly focused on brain structures (López-López et al., 2016). 
151 Previous proteomic analysis of liver from mouse under chronic unpredictable mild stress

152 (CUMS) paradigm for five weeks showed alterations in proteins related to inflammation,

153 immune regulation, lipid metabolism, and NF-אB signaling network (Wu et al., 2016).

154 Briefly, the liver is closely connected with the central nervous system, and in distress, both suffer

155 significant changes. Both brain and liver are highly implicated in the maintenance the body

156 homeostasis under stress conditions, and studies about the impact of oxidative stress on the

157 brain-liver axis are very limited. Neuroprotective drugs, like piracetam, are used to diminish the

158 effect of free radicals. Thereby, proteomic studies in the liver about the impact of this drug in

159 distress are needed to evaluate also possible protective effects. The present study aimed to assess

160 the consequence of distress and piracetam on the female rats' health by the analysis of behavior,

161 plasma biochemical parameters, liver proteome, and antioxidant enzyme activity.

162

163 Materials \& Methods

\section{Animals and experimental design}

165 Twenty-eight healthy adult female Sprague-Dawley rats (Rattus novergicus) of $10-12$ weeks of

166 age, weighing $170 \mathrm{~g}$ to $270 \mathrm{~g}$, were used. The animals were maintained in a controlled

167 environment in light-dark cycle of $12 / 12$ hours, under room temperature conditions of $24 \pm 2{ }^{\circ} \mathrm{C}$,

168 with food and water ad libitum. The animals were kept in pairs in standard plastic cages with no

169 enriched environment. Five days before the experiment were housed individually to minimize

170 the stress by separation. Rats were purchased in Rismart, S.A. de C.V., México.

171 The experimental design was carried out for six days. The induction of distress was performed in

172 the first five days, and the rats were sacrificed on the sixth day. Each day, before distress

173

174

175 exposure, rats belonging to the treatment group received piracetam and rats belonging to the control group received the same amount of water instead of the drug (Fig. S1 A). The rats were randomly allocated by drawing lots into four experimental groups ( $\mathrm{n}=6-7$ for each group): rats

176

177

178

179

180

181

182 neither exposed to stressor nor with piracetam treatment ( $\mathrm{S}-\mathrm{P}-)$, rats exposed to stressor without piracetam treatment $(\mathrm{S}+\mathrm{P}-)$, rats not exposed to stressor but treated with piracetam $(\mathrm{S}-\mathrm{P}+)$, and rats exposed to stressor and treated with piracetam $(\mathrm{S}+\mathrm{P}+)$ (Fig. S1C). No animal exclusions during the experiments were made in this study.

\section{Administration of piracetam and distress induction}

Piracetam (Nootropil ${ }^{\circledR}(1 \mathrm{~g} / 5 \mathrm{~mL})$, UCB Pharma Belgium) was administered as a single oral dose of $600 \mathrm{mg} / \mathrm{kg}$ in a final volume of $600 \mu \mathrm{L}$ using a cannula, for six days, always at the same time $(7: 30 \mathrm{am})$ (Fig. S1A).

186 Every day, the induction of distress was carried out after the administration of piracetam from 8:00 am to 9:00 am. For it, a special box $(60 \times 27 \times 35 \mathrm{~cm})$ made of plastic was used, with the third part of black walls (the part of the box where the animals can hide, the black box) and two parts with transparent walls, separated by a black room divider with a small entrance through which the animal can pass (Dielenberg \& McGregor, 2001) (Fig. SlB). Rats were left inside the boxes for $20 \mathrm{~min}$ to habituate to the new habitat. After this time, the animals were returned to their housing cage for 20 minutes to relax. Meanwhile, the box was conditioned by placing a 20 x $20 \mathrm{~cm}$ white cloth in the transparent part: a clean cloth was placed for the control group while,

193 for the distressed group, the piece of cloth was previously placed in contact with a domestic cat

194 for several days (as a cat rug). Next, rats were transferred to the experimental boxes for another

$19520 \mathrm{~min}$. Each piece of cloth was stored in hermetic plastic bags and stored at $-20^{\circ} \mathrm{C}$ until its next 
196 use. The rats were videotaped for further behavior analysis using JWatcher ${ }^{\mathrm{TM}} \mathrm{v} 0.9$ software, and

197 the obtained data were expressed as the full time spent in each specific position each day

198 (Grigoruţă et al., 2018).

199 All experiments were approved by the Institutional Committee of Ethics and Bioethics from the

200 Universidad Autónoma de Ciudad Juárez, Ciudad Juárez, Chihuahua, México (No.CIBE-2017-1-

201 34), following the Official Mexican Norm (NOM-062-ZOO-1999) and the ARRIVE guidelines

2022.0 (du Sert et al., 2020). No humane endpoints were needed in this study.

203

204

205

206

207

208

209

210

211

212

213

214

215

216

217

218

219

220

221

222

223

224

225

226

227

228

229

230

231

232

233

234

235

236

237

238

239

240

241

\section{Sample collection}

On the sixth day, animals were intraperitoneally anesthetized using sodium pentobarbital (45 $\mathrm{mg} / \mathrm{kg}$ ). After the loss of sensitivity and motor reflexes, whole blood samples were collected by cardiac puncture using vacutainer EDTA tubes for plasma biochemical parameter analysis. Further, rats were decapitated and, finally, the liver was extracted and weighted. One gram of liver was aliquoted for enzymatic activity assays and the rest of it was stored at $-80{ }^{\circ} \mathrm{C}$ for proteomic analysis (Fig. S1C).

\section{Blood plasma biochemical parameter analysis}

The whole blood was centrifugated at $1,500 \times \mathrm{g}$ for $10 \mathrm{~min}$. Then, the fresh plasma was collected and measured using a Cobas ${ }^{\circledR} \mathrm{c} 111$ analyzer (Roche) for each biochemical parameter with the reagents provided by the manufacturer, following the manufacturer's specifications (Fig. SIC).

\section{Liver enzyme activity assays}

Fresh liver aliquots $(1 \mathrm{~g})$ were homogenized (weight/volume 1:10) in cold $50 \mathrm{mM}$ phosphate buffer $\left(\mathrm{K}_{2} \mathrm{HPO}_{4}, \mathrm{KH}_{2} \mathrm{PO}_{4}\right.$, pH 7.4), with $1 \%$ phenylmethylsulfonyl fluoride (PMSF). After homogenization, the samples were sonicated three times for $30 \mathrm{~s}$, with 1 min pause between each round, over the ice. Further, these samples were separated into aliquots for the different enzymatic activity methodology $(n=3-5)$. For catalase (CAT) activity analysis, the samples were centrifugated at $52 \mathrm{xg}$ for $20 \mathrm{~min}$ at $4{ }^{\circ} \mathrm{C}$. For the study of the enzymatic activity of superoxide dismutase (SOD), glutathione-S transferase (GST), glutathione peroxidase (GPX), and glutathione reductase (GR), the samples were centrifugated at $20,800 \times \mathrm{g}$ for $30 \mathrm{~min}$ at $4{ }^{\circ} \mathrm{C}$, as previously described (Mejia-Carmona et al., 2014, 2015). In both cases, the supernatants were stored at $-80{ }^{\circ} \mathrm{C}$ till use. Enzyme activity was measured by spectrophotometry using a microplate reader FLUOstar Omega (BMG) for 96-wells plates (Fig. S1C).

CAT activity was determined according to the method of Aebi (1984) with small modifications (Aebi, 1984). As an oxidant medium was used $14 \mathrm{mM} \mathrm{H}_{2} \mathrm{O}_{2}$ (Sigma-Aldrich, H1009) in $0.1 \mathrm{M}$ phosphate buffer $\left(\mathrm{K}_{2} \mathrm{HPO}_{4}, \mathrm{KH}_{2} \mathrm{PO}_{4}, \mathrm{pH}\right.$ 7.4), and the sample was added in a final volume of 220 $\mu \mathrm{L}$ per well. Kinetic measurements were obtained at $240 \mathrm{~nm}$ (Mejia-Carmona et al., 2014). One unit of the enzyme represents the quantity of CAT used to neutralize one $\mu \mathrm{M}$ of peroxide per $\min$.

SOD activity was determined by autooxidation of pyrogallol, a method developed by Marklund and Marklund (Marklund \& Marklund, 1974). This method is based on the ability of pyrogallol for autooxidation, capturing the superoxide radicals at $\mathrm{pH} 8.2$ and developing a yellow color that can be detected spectrophotometrically. SOD eliminates the radicals from de media and inhibits the pyrogallol oxidation. Total SOD and mitochondrial SOD (SOD2) activity were measured in $50 \mathrm{mM}$ Tris-HCl, $\mathrm{pH} 8.2$, containing $1 \mathrm{mM}$ dietilentriaminopentaacetic acid (DTPA) as an oxidant medium. For the SOD2 activity, $110 \mathrm{mM}$ sodium cyanide $(\mathrm{NaCN})$ solution was also 
242 added to inhibit the specific activity of cytosolic SOD (SOD1). Finally, pyrogallol (Sigma

243 254002) solution was automatically injected by the microplate reader reaching a final

244 concentration of $4 \mathrm{mM}$ in a total volume of $300 \mu \mathrm{L}$ per well, and kinetic measurements were

245 obtained at $450 \mathrm{~nm}$, as previously described (Mejia-Carmona et al., 2015). One unit of SOD was

246 considered as the concentration of enzyme used to inhibit $50 \%$ of pyrogallol autooxidation.

247 Specific enzyme activity of SOD1 was calculated as the difference between the enzyme activity

248 of total SOD and SOD2.

249 The GST activity was determined according to the method of Habig et al. (Habig, Pabst \&

250 Jakoby, 1974) with some modifications. This method is based on the capacity of glutathione to

251 combine with 1-chloro-2,4-dinitrobenzene (CDNB) to form the complex glutathione-CDNB. A

$2520.1 \mathrm{M}$ Phosphate buffer $\left(\mathrm{K}_{2} \mathrm{HPO}_{4}, \mathrm{KH}_{2} \mathrm{PO}_{4}, \mathrm{pH} 6.5\right)$ containing $2.25 \mathrm{mM}$ CDNB (Sigma,

253 237329) and $2.25 \mathrm{mM}$ reduced glutathione (GSH, Sigma-Aldrich, G4251) was used as the

254 substrate solution. Further, the sample was added in a final volume of $225 \mu \mathrm{L}$ in each well.

255 Kinetic measurements were obtained at $340 \mathrm{~nm}$, as previously described (Mejia-Carmona et al.,

256 2015). One unit of the enzyme activity was considered as the concentration of the GST necessary

257 to obtain one $\mu \mathrm{M}$ of the complex glutathione-CDNB per min.

258 GPX activity was determined according to Weiss et al. (Weiss, Maker \& Lehrer, 1980) with

259 some modifications. This method is based on the measurement of the disappearance of reduced

260 nicotinamide adenine dinucleotide phosphate (NADPH). Fresh substrate solution was prepared

261

262

263

264

265

266

267

268

269

270

271 in $0.1 \mathrm{M}$ phosphate buffer $\left(\mathrm{K}_{2} \mathrm{HPO}_{4}, \mathrm{KH}_{2} \mathrm{PO}_{4}, \mathrm{pH}\right.$ 7.4) containing $2 \mathrm{mM}$ EDTA, $1.4 \mathrm{U}$ glutathione reductase (Roche, 10105678001), $1 \mathrm{mM} \mathrm{GSH,} 0.2 \mathrm{mM} \mathrm{NADPH,} 0.5 \mathrm{mM} \mathrm{H}_{2} \mathrm{O}_{2}$ (Sigma-Aldrich, H1009) and $1 \mathrm{mM} \mathrm{NaCN}$. The substrate solution and the sample were added to each well in a final volume of $300 \mu \mathrm{L}$. Kinetic measurements were obtained at $340 \mathrm{~nm}$. One unit of enzyme activity represents the concentration of GPX that oxidizes one $\mu \mathrm{M}$ of NADPH per $\min$.

The method used for the study of GR activity is based on the measurement of the reduction of NADPH, as previously published by Weiss et al. (Weiss, Maker \& Lehrer, 1980) with few modifications. The substrate solution was prepared from $20 \mathrm{mM}$ oxidized glutathione (GSSG) (Abcam, ab141393) and $2 \mathrm{mM}$ NADPH (Sigma-Aldrich, N5130) diluted in $0.1 \mathrm{M}$ phosphate buffer $\left(\mathrm{K}_{2} \mathrm{HPO}_{4}, \mathrm{KH}_{2} \mathrm{PO}_{4}, \mathrm{pH} 7.4\right)$ with $2 \mathrm{mM}$ EDTA. The substrate solution and the sample

272

273

274

275

276

277

278

279

280

281

282

283

284

285

286

287 were added to each well in a final volume of $300 \mu \mathrm{L}$. Kinetic measurements were obtained at $340 \mathrm{~nm}$. One unit of enzyme activity represents the concentration of GR that oxidizes one $\mu \mathrm{M}$ of NADPH per min.

\section{Liver protein extraction}

The remaining liver was lyophilized and grounded using a mortar and a pestle. For protein extraction, a TCA/acetone-based method was used. Briefly, $600 \mu \mathrm{L}$ of cold precipitation solution $(10 \%(\mathrm{w} / \mathrm{v}) \mathrm{TCA} ; 100 \%(\mathrm{v} / \mathrm{v})$ acetone, $0.07 \%(\mathrm{w} / \mathrm{v})$ DTT) was added on $40 \mathrm{mg}$ of pulverized liver. Samples were sonicated 6 x $10 \mathrm{~s}$ at $30 \mathrm{w}(6.9 \mathrm{kHz}$; Sonic Dismembrator, Model 100, Fischer Scientific) and let to precipitate at $-20{ }^{\circ} \mathrm{C}$ overnight. Subsequently, the samples were centrifuged at $18,500 \times \mathrm{g}$ for $10 \mathrm{~min}$ at $4{ }^{\circ} \mathrm{C}$ and the supernatant was decanted. Then, pellets were twice washed using $1 \mathrm{~mL}$ of cold washing solution $(80 \%(\mathrm{v} / \mathrm{v})$ acetone, $0.07 \%(\mathrm{w} / \mathrm{v})$ DTT) (González-Fernández et al., 2014). Finally, protein pellets were dried at room temperature to eliminate acetone residue. Proteins were solubilized using $100 \mu \mathrm{L}$ of a solution containing $7 \mathrm{M}$ urea, $2 \mathrm{M}$ thiourea, $4 \%$ (w/v) CHAPS, $0.5 \%$ (w/v) Triton X-100, $20 \mathrm{mM}$ DTT, $1 \mathrm{mM}$ PMSF. Proteins were quantified using the Bradford assay (Bradford Reagent, B6916, Sigma-Aldrich $\AA$ ),

Peer] reviewing PDF | (2020:11:55760:1:0:NEW 31 Mar 2021) 
288

289

290

291

292

293

294

295

296

297

298

299

300

301

302

303

304

305

306

307

308

309

310

311

312

313

314

315

316

317

318

319

320

321

322

323

324

325

326

327

328

329

330

according the manufacturer's procedure. For the protein identification, $50 \mu \mathrm{g}$ of total proteins extracted from each liver were pooled $(\mathrm{n}=6-7)$ for each experimental group (Fig. S1C).

\section{GeLC-MS/MS analysis}

The protein identification was performed using one-dimensional sodium dodecyl sulfatepolyacrylamide gel electrophoresis (1D-SDS-PAGE) coupled by liquid chromatography-tandem mass spectrometry (GeLC-MS/MS) analysis (Fig. S1C). A total of $100 \mu \mathrm{g}$ of pooled proteins from each experimental group was pre-separated by 1D-SDS-PAGE, gels were stained by the Coomassie method, and finally, each gel band was dissected manually in three equal parts. In-gel protein digestion and nano LC-MS/MS were performed according to the methodology previously described (Espinosa-Gómez et al., 2020) (for the complete description of the methodology carried out in this analysis, see Methodology S1). Briefly, firstly, each gel section was distained, and then dehydrated. Finally, proteins in gel sections were reduced with DTT and alkylated with iodoacetamide. For in-gel digestion, the gels sections were incubated in a solution containing $12.5 \mathrm{ng} / \mu \mathrm{L}$ mass spectrometry grade Trypsin Gold (Promega, Madison, WI, USA) in $5 \mathrm{mM}$ $\mathrm{NH}_{4} \mathrm{HCO}_{3}$, at $37^{\circ} \mathrm{C}$ overnight. Peptide samples were analyzed using an UltiMate 3000 RSnanoLC system (Thermo-Fisher Scientific, San Jose, CA) interfaced with Orbitrap Fusion ${ }^{\mathrm{TM}}$ Tribid $^{\text {TM }}$ (Thermo-Fisher Scientific, San Jose, CA) mass spectrometer. All MS data were obtained through Xcalibur 4.0.27.10 software (Thermo-Fisher Scientific) (Espinosa-Gómez et al., 2020). Each sample of pooled proteins for each experimental group was run on one time.

\section{Proteomics data analysis and biological interpretation}

Mass spectra were analyzed with Proteome Discoverer 2.1 software (PD, Thermo Fisher Scientific Inc.). The later searches were performed through Mascot server (version 2.4.1, Matrix Science, Boston, MA), SEQUEST HT (Eng, McCormack \& Yates, 1994), and AMANDA (Dorfer et al., 2014). For protein identification, 25, 3.7, and 200 scores were considered, respectively, for each search engine. The search with each engine was conducted against the UniProt rat reference proteome ( $R$. novergicus) database (https://www.uniprot.org/proteomes/UP000002494) (for the complete description of the protein search parameters in this analysis, see Methodology S1). The exponentially modified protein abundance index (emPAI) was calculated for the label-free relative quantitation of the proteins in each sample analyzed by nanoLC-MS/MS (Shinoda, Tomita \& Ishihama, 2009). Only proteins identified with at least two unique peptides and a 1.5-fold difference in their relative abundance $(0.66 \leq$ fold change $\geq 1.50)$ were considered for further analysis.

Gene Ontology (GO) analysis and protein network were performed using the Search Tool for the Retrieval of Interacting Genes/Proteins (STRING) (https://stringdb.org/cgi/input?sessionId=b8yhKk9BbQSn\&input_page_show_search=on) (Szklarczyk et al., 2019). Enrichment pathway analysis was carried out using the Gene Annotation \& Analysis Resource Metascape (http://metascape.org/gp/index.html\#/main/step1) (Zhou et al., 2019). The enrichment cluster analysis was made using the following settings: $p$-value $<0.01$, minimum count of 3, enrichment factor $>1.5$, and FDR $>0.05$.

\section{Statistical analysis}


331 The normality of the animal behavior, the antioxidant enzyme activity, and the biochemical plasma data were tested using the Kolmogorov-Smirnoff (KS) test. Furthermore, for the descriptive data, one-way ANOVA and Pearson's correlation coefficient (rho) were determined, considering a statistically significant of $\mathrm{p} \leq 0.05$. The statistical analysis was performed using SPSS v.8.0 software (SPSS Inc. Chicago, IL, USA).

336

337

\section{Results}

\section{Protein identification by GeLC-MS/MS approach}

To evaluate the effect of the chronic psychological distress and piracetam on female rat liver proteome, proteins were extracted using a TCA-acetone-based method. Protein samples from each liver were pooled ( $\mathrm{n}=6-7)$ and pools from each experimental condition were subjected to a pre-separation by 1D SDS-PAGE. Then, proteins were in-gel digested by trypsin, extracted from gel pieces and analyzed by a shotgun proteomic approach. Each experimental group was analyzed independently by label-free relative quantitation using the emPAI values. A total of 1,302 proteins were identified with at least one unique peptide and $1 \%$ FDR (Data S1). Of these, 894 proteins with at least two unique peptides were considered for further analysis. The intersection of proteins identified in all the experimental conditions was shown by a Venn diagram (Fig. 1A). A 1.5-fold change threshold was used as cut-off values for protein abundance changes ( $50 \%$ of value variation). According to this criterion, a total of 350 proteins exhibited qualitative differences between the four conditions: 112 proteins were found unique in one of the four experimental conditions, 103 were presented only in two of the four groups, and 135 in three groups (Fig. 1A). Regarding the quantitative differences, 313 proteins showed a change in their abundance comparing $\mathrm{S}+\mathrm{P}-$ versus $\mathrm{S}-\mathrm{P}-, 259$ proteins in $\mathrm{S}+\mathrm{P}-$ versus $\mathrm{S}+\mathrm{P}+$, and 315 proteins in $\mathrm{S}-\mathrm{P}+$ versus $\mathrm{S}-\mathrm{P}-($ Data $\mathrm{S} 2)$.

Gene Ontology through STRING search tool annotation was used to determine the subcellular localization of all proteins identified. The most highly represented categories in this study were membrane-associated, mitochondrial, cytosolic, and nuclear proteins, counting more than 100 proteins in each category (Fig. 1B).

\section{Biological interpretation of differentially accumulated proteins}

\section{Proteins function was analyzed using Kyoto Encyclopedia of Genes and Genomes (KEGG)} annotation through Metascape online tool (Fig. 2). Liver from rats exposed to distress (S+P-) showed significant enrichment in 16 pathways in which proteins were less abundant, and in 31 pathways in which proteins were more abundant compared to the liver from rats not exposed to distress (S-P-) (Fig. 2A). In general, proteins related to amino acids metabolism, glucose and fatty acid (FA) mobilization and degradation to produce energy (glycolysis/gluconeogenesis, TCA cycle, pyruvate metabolism, FA degradation, PPAR signaling pathway, dicarboxylate metabolism, butanoate metabolism), protein folding, trafficking and degradation, metabolism of xenobiotics by cytochrome P450, GSH metabolism, antioxidant defense mechanisms, and nonalcoholic fatty acid liver or Parkinson's diseases, among others, were highly affected in distress $(\mathrm{S}+\mathrm{P}-)$ when compared to $\mathrm{S}-\mathrm{P}-($ Fig. $2 A$, Data S3). 
372 When piracetam was supplied to the distressed group $(\mathrm{S}+\mathrm{P}+), 24$ and 19 pathways showed a

373 significant enrichment in which proteins were less and more abundant, respectively, compared to

$374 \mathrm{~S}+\mathrm{P}-$ (Fig. 2B). Piracetam reverted the changes in metabolism caused by distress exposure (Fig.

$3752 A$ and $2 B$, Data $S 3)$. When piracetam was administrated to non-distressed rats ( $\mathrm{S}-\mathrm{P}+), 16$ and

37634 pathways showed a significant enrichment in which proteins were less and more abundant,

377 respectively, compared to the control group (S-P-) (Fig. 2C). The functional enrichment

378 analysis showed that proteins involved in amino acid metabolism, both biosynthesis and

379 especially degradation pathways, and in the oxidation of glucose and fatty acids were more

380 abundant. In the same way, proteins involved in the metabolism of xenobiotics by cytochrome

$381 \mathrm{P} 450$ and GSH showed an increase in their abundance (Fig. 2A and 2C,Data S3).

382 This study highlights that psychological distress and piracetam induce changes in protein

383 abundances that are involved in redox metabolism, non-alcoholic fatty liver disease (NAFLD),

384 ER stress, and metabolism of xenobiotics by Cyt P450.

385

386

387

388

389

\section{Altered proteins involved in redox metabolism}

In this study, a total of 26 proteins involved in redox homeostasis were detected in the hepatic proteome, of which 19 of them presented differences in $50 \%$ in protein abundance changes between $\mathrm{S}+\mathrm{P}-$ versus $\mathrm{S}-\mathrm{P}-, \mathrm{S}+\mathrm{P}+$ versus $\mathrm{S}+\mathrm{P}-$, and $\mathrm{S}-\mathrm{P}+$ versus $\mathrm{S}-\mathrm{P}-(0.66 \leq$ fold change $\geq$ 1.50) (Table $S 1)$.

392 To validate the changes in redox enzymes found in the proteomic analysis, the activity of the selected antioxidant enzyme was also measured by biochemical methods (Table 1, Data S4). Although no change in GPX protein abundance was shown in distressed rats (Table S1), a statistically significant increase about two-fold in the GPX activity was observed in this condition $(\mathrm{p}=0.026)($ Table 1$)$, and piracetam decreased this effect by $10 \%$, but without resetting the control group values (Tables 1 and $S 1$ ); however, the drug increased the protein abundance in $75 \%$ in the distressed rats $(\mathrm{S}+\mathrm{P}+)($ Table $\mathrm{S} 1)$. When piracetam was administered to non-distressed animals $(\mathrm{S}-\mathrm{P}+)$ also induces a statistically significant rise of more than $70 \%$ in GPX activity.

An increase of $50 \%$ in CAT protein abundance was observed in rat liver exposed to stress stimuli (Table S1); however, no significant changes in CAT activity were shown in this group (Table 1). Piracetam induced a statistically significant decrease of $20 \%$ in the CAT activity in distressed group $(\mathrm{S}+\mathrm{P}+)$, and this reduction was about $25 \%$ in non-distressed animals $(\mathrm{S}-\mathrm{P}+)(\mathrm{p}$ $=0.044$ ) (Table 1). The drug enhanced the CAT abundance by $18 \%$ in the distressed group $(\mathrm{S}+\mathrm{P}+)$ compared to $\mathrm{S}+\mathrm{P}-$ group and induced its increase for about $40 \%$ in non-distressed

407 Distress and piracetam induced no changes in total GST activity (Table 1); however, ten GST 408 isoforms were found in the proteomic analysis with different trend in protein abundance changes 409 (Table S1). Glutathione S-transferases, specifically glutathione S-transferase A4-4 (GSTA4), 410 keep in balance the cellular 4-hydroxynonenal (4-HNE) concentration, an end-product of n-6 411 PUFAs peroxidation related to increased apoptosis and necrosis, through its conjugation to GSH 
412 (Singhal et al., 2015). In this study, the GSTA4 was found $50 \%$ less abundant in the distressed

413 group ( $\mathrm{S}+\mathrm{P}-)$; however, piracetam produced an increase of two-fold in the abundance of this 414 protein in distressed rats $(\mathrm{S}+\mathrm{P}+)($ Table $\mathrm{S} 1)$.

415 Also, GR and SOD (total SOD, SOD1, SOD2) showed no activity changes induced by distress in

416 the liver (Table 1). In LC-MS/MS analysis, GR and SOD2 abundance were not detected but

417 SOD1 abundance was found $50 \%$ decreased in $\mathrm{S}+\mathrm{P}-$ compared to $\mathrm{S}-\mathrm{P}-$ - Piracetam decreased

418 its abundance in animals under distress exposure (with $30 \%, \mathrm{~S}+\mathrm{P}+$ versus $\mathrm{S}+\mathrm{P}-$ ) and induced a

419 decrease even more in no-distressed rats (with $70 \%$, $\mathrm{S}-\mathrm{P}+$ versus $\mathrm{S}-\mathrm{P}-$ ) (Table S1).

420

421

\section{Altered proteins involved in non-alcoholic fatty liver disease (NAFLD)}

422

423

One of the pathways affected by distress and piracetam, in the present study, was related to NAFLD (rno04932) (Fig. 2). A total of 11 and 9 proteins were increased and decreased, respectively, under distress exposure (Table S2). Proteins from NADH dehydrogenase (Complex I), Cytochrome b-c1 complex (Complex III), response to oxidative stress, and apoptosis regulation were decreased, and this tendency was inverted by piracetam (Table S2).

427

428

429

430

431

432

433

434

435

436

\section{Altered proteins involved in ER stress}

The endoplasmic reticulum (ER) is an essential organelle involving in protein folding and trafficking, calcium homeostasis and is widely developed in hepatocytes. In this study, the protein processing in ER ( $(n 004141)$ was affected by distress exposure ( $\mathrm{S}+\mathrm{P}-$ ), causing a change in the abundance of proteins involved in the ER quality control by the retention of incorrectly folded proteins, in the ubiquitin-proteasome system, autophagy, and ER-associated protein degradation pathway, and in the protein processing, transport and secretion (Fig. 2A, Table S3). Piracetam provoked a shift in the abundance of proteins that were found less abundant in the liver of distressed animals $(\mathrm{S}+\mathrm{P}+)$ (Fig. 2B, Table S3) but had no effect on those that were more abundant; moreover, the drug had no effect on non-distressed animals ( $\mathrm{S}-\mathrm{P}+)$ (Fig. 2C, Table S3). Besides, the ER stress could be assisted by the activation of the peroxisome proliferatoractivated receptors (PPARs) signaling pathway (rno03320), which has been shown to mediate hepatic protection (Zhang et al., 2016). In this study, the PPAR signaling pathway was increased in distressed animals $(\mathrm{S}+\mathrm{P}-$ ) and by piracetam (in $\mathrm{S}+\mathrm{P}+$ and $\mathrm{S}-\mathrm{P}+$ groups versus $\mathrm{S}-\mathrm{P}-$ group)

443 (Fig. 2, Table S3).

\section{5}

446

447

448

449

450

451

\section{Altered proteins involved in the metabolism of xenobiotics by Cyt P450}

The biotransformation process involving Phases I and II enzymes of xenobiotics and drug metabolism was also affected by exposition to the stressor (rno00980) (Fig. 2A, Table S3). One of the proteins that turned out to be the most abundant in the liver of stressed rats was the cytochrome P450 2E1 (CYP2E1), which has been associated with steatohepatitis development. In this study, this protein was more abundant in animals exposed to distress $(\mathrm{S}+\mathrm{P}-)$. Piracetam induced its decline in distressed rats $(\mathrm{S}+\mathrm{P}+)$ but increased it in non-distressed ones $(\mathrm{S}-\mathrm{P}+)$ compared to the control group ( $\mathrm{S}-\mathrm{P}-$ ) (Fig. $2 B$ and $C$, Table S3). 


\section{Interaction network of differently accumulated proteins}

455

456

457

458

459

460

461

462

463

464

465

466

467

468

469

470

471

472

473

474

475

476

477

478

479

480

481

482

483

484

485

486

487

488

489

490

491

A Markov Clustering (MCL) algorithm was applied to identified proteins with abundance changes involved in PD (rno05012), NAFLD (rno04932), selected antioxidant enzymes (included in Table 1), PPAR signaling pathway (rno03320), processing in ER (rno04141), proteasome (rno03050), cytochrome P450 metabolism (rno00980), and selected proteins involved in apoptosis (caspase 6 (CASP6) and apoptosis-inducing factor 1, mitochondrial (AIFM1)) to show the associations among them, using de STRING protein-protein interaction database. These proteins were grouped into sixteen clusters (Fig. 3, Data S5). The protein interaction network showed a close relationship among these pathways. These clusters can be grouped into five sets and are distributed around a central group with proteins involved in redox status homeostasis as DJ-1, SOD1, CAT, GLRX5, PRDX2, PRDX5, PRDX6, and TXNRD1 (proteins in cluster 6, colored like green; see cluster information in Data S5).

\section{Effect of chronic psychological distress and piracetam on animal behavior}

Four of the rat behaviors were more common during the $20 \mathrm{~min}$ exposure to distress each day and were expressed as the time spent in each position (Dielenberg \& McGregor, 2001; Grigoruţă et al., 2018) (Fig. 4, Data S4): two defensive behaviors that included hide, referring to the time the rat spent in the hiding place (Fig. 4A), and head-out, like the time the rat is spending in alarm position with the head out or with half of the body out from the hiding place, observing the horizon (Fig. 4B); and two non-defensive behaviors that included exploration, like the time the rat spent exploring the transparent part of the box (Fig. 4C), and approach, like the time the rat spent smelling the piece of cloth with or without cat odor stimuli (Fig. 4D). Rats exposed to cat odor stimuli $(\mathrm{S}+\mathrm{P}-)$ were concealed in the hiding place during almost all the time of the distress exposure in all five days ( $97 \%$ of the total time) (Fig. 4A), comparing to non-distressed rats $(\mathrm{S}-\mathrm{P}-)(\mathrm{p} \leq 0.00001)$, that spent more time exploring the open place $(4 \%, \mathrm{p} \leq 0.0001)$, in head out position $(12 \%, \mathrm{p} \leq 0.0000001)$, and approaching the cloth $(5 \%, \mathrm{p}=0.032)$, from the second day (Fig. $4 B, C, D$ ). These observations showed the efficiency of the distress induction model by cat odor exposure.

Piracetam did not change the behavior in distressed rats $(\mathrm{S}+\mathrm{P}+)($ Fig. 4). However, when the drug was administrated to non-distressed rats $(\mathrm{S}-\mathrm{P}+)$, significant changes were observed compared to the control group ( $\mathrm{S}-\mathrm{P}-$ ), increasing of $78 \%$ to $93 \%$ the time spent in the concealment, while the time used to explore, to approach the cloth and to be in the alert was decreased, as happened in $\mathrm{S}+\mathrm{P}-$ group (Fig. 4).

\section{Effect of chronic psychological distress and piracetam on plasma biomarkers}

Several biochemical parameters including glucose, triglycerides, and cholesterol and other biomarkers that indicate liver function (direct and indirect bilirubin, alanine aminotransferase, aspartate aminotransferase, total protein, and albumin levels) and kidney function (creatinine, urea, and blood urea nitrogen (BUN) levels) were measured in plasma in all experimental groups 
492 (Table 2, Data S4). The exposure to chronic distress induced a statistically significant decrease in 493 glucose levels in the distressed group $(\mathrm{S}+\mathrm{P}-)(\mathrm{p}=0.012)$, and the administration of piracetam 494 avoided such an effect. The same happened in the triglycerides level, albeit not significant 495 changes. The specific biomarkers for hepatic injury and function were not affected by distress

496

497

498

499

500

501

502

503

504

505

506

507

508

509

510

511

512

513

514

515

516

517

518

519

520

521

522

523

524

525

526

527

528

529

530

531 and/or piracetam, although the total bilirubin presented a tendency to decrease in distressed animals $(\mathrm{S}+\mathrm{P}-)$ and with piracetam $(\mathrm{S}+\mathrm{P}+)(\mathrm{p}=0.065)$. Moreover, a statistically significant increase in the BUN level was found in distressed animals $(\mathrm{S}+\mathrm{P}-)$, and piracetam counteracted this effect reducing such levels, even more in rats exposed to distress $(\mathrm{S}+\mathrm{P}-)(\mathrm{p}=0.025)$. Also, piracetam significantly decreased plasma urea levels in distressed rats $(\mathrm{S}+\mathrm{P}+)$ compared to untreated rats $(\mathrm{S}+\mathrm{P}-)(\mathrm{p}=0.025)$.

\section{Correlational analysis among treatments, behavior, biochemical parameters, and antioxidant enzyme activity}

To study the association between treatments and behavior, a normality test of the variables was first performed using Kolmogorov-Smirnoff (KS). Normal data distribution was shown and therefore the statistical test Pearson's correlation coefficient (rho) was used, considering a statistically significant correlation $\mathrm{p} \leq 0.05$. A high correlation was found between treatments and behaviors (Table S4). The time spent hiding was positively correlated with the treatments $(\mathrm{r}$ $=0.82, \mathrm{p} \leq 0.00001$ ), while the time spent in head-out position, exploring and approaching the piece of cloth were negatively correlated with the treatments $(\mathrm{r}=-0.73, \mathrm{r}=-0.83$, and $\mathrm{r}=-0.72$, respectively; $\mathrm{p} \leq 0.0001$ ) (Fig. S2). These correlations showed that piracetam had no effect on distressed rats but induced defensive behavior in non-distressed rats (Grigoruţă et al., 2018). Further, correlational studies among biochemical parameters, antioxidant enzyme activity, treatments, and rat behavior were performed. The indirect and total bilirubin were negatively correlated with the treatments $(\mathrm{r}=-0.63, \mathrm{p}=0.02$ and $\mathrm{r}=-0.58, \mathrm{p}=0.01$, respectively) (Table S4). Moreover, glucose level was negatively correlated with the time spent hiding $(\mathrm{r}=-0.49, \mathrm{p}=$ 0.04) (Fig. S2A, Table S4), while it was positively correlated with the time spent in head out position $(\mathrm{r}=0.57, \mathrm{p}=0.04)$ (Fig. $S 2 B$, Table $S 4)$; direct bilirubin level was positively correlated to the time spent approaching and exploring $(\mathrm{r}=0.67, \mathrm{p}=0.01$ and $\mathrm{r}=0.59, \mathrm{p}=0.03$, respectively) (Fig. S2C, D, Table S4); and total bilirubin level was negatively correlated with the time spent hiding $(\mathrm{r}=-0.45, \mathrm{p}=0.05)$ (Fig. $S 2 E$, Table $S 4)$, and positively correlated with the time spent exploring $(\mathrm{r}=0.45, \mathrm{p}=0.05)$ (Fig. $S 2 F$, Table $S 4)$. These correlations between behavior and biochemical parameters show that bilirubin levels are related to stress behavior and can be useful as a biomarker of psychological distress.

The correlational analysis among antioxidant enzyme activity with rat behavior and treatments showed that only GPX activity had a positive association with the treatments $(\mathrm{r}=0.61, \mathrm{p}=0.01)$ (Table S4) and with the time spent hiding $(\mathrm{r}=0.55, \mathrm{p}=0.01)$ (Fig. S2G), and it had negative association with the exploration time $(\mathrm{r}=-0.61, \mathrm{p}=0.01)$ (Fig. $S 2 H)$. These correlations support the relationship of this enzyme with the stress behavior of hiding and it can be considered in future studies as a distress biomarker. 


\section{Discussion}

534 The connection between the physiological effects induced by oxidative stress and inflammation

535

536

537

538

539

540

541

542

543

544

545

546

547

548

549

550

551

552

553

554

555

556

557

558

559

560

561

562

563

564

565

566

567

568

569

570

571 caused by psychological distress and the associated pathologies is still unclear how occurs, as well as the questionable beneficial effects of piracetam. The proteomic analysis provides a global view of the affected cellular processes and the possible consequences on the body. Thus, a GeLC-MS/MS analysis followed by a label-free relative quantitation based emPAI values of identified proteins were carried out. Overall, our results showed that distress affected a wide range of proteins involved in amino acid metabolism, glucose, and fatty acid (FA) mobilization and degradation to produce energy, protein folding, trafficking and degradation, redox metabolism, and NAFLD development. Piracetam reverted the changes in metabolism caused by distress exposure, and, under physiological conditions, the drug induced an increased catabolism rate directed towards energy production.

Physiologically, the body's primary response to stress is the fight or flight response that, at the metabolic level, involves an increase of the energy production rate (increase ATP). After exposure to a stressor, the hypothalamic-pituitary-adrenal axis is activated, causing the production of the so-called stress hormones, such as epinephrine and cortisol (corticosterone in murine), which in turn cause an increase of glycogenolysis, gluconeogenesis, lipid mobilization, and inhibition of protein synthesis. Also, ATP synthesis leads to ROS generation, which can promote oxidative stress, causing cellular damage to DNA, lipids, and proteins (Schiavone et al., 2013; Dumbell, Matveeva \& Oster, 2016). Previous studies showed that emotional stress induces oxidative damage and altered metabolism in the liver in different murine psychological stress models (Depke et al., 2008, 2009; Jafari et al., 2014).

In the present study, we focused on liver proteins involved in redox metabolism, NAFLD, ER stress, and metabolism of xenobiotics by Cyt P450, which were changed by psychological distress and piracetam.

\section{Redox metabolism}

The maintenance of optimal ROS levels is essential in the body due to the dual function of these species. ROS are signaling molecules that activate transcription factors that regulate the gene expression related to growth and cell differentiation, but, on the other hand, ROS excess has been associated with the development of numerous diseases such as type 2 diabetes, autoimmune diseases, cancer or neurodegenerative diseases, among all (Hackett \& Steptoe, 2017; Wadhwa \& Maurya, 2018; Sharif et al., 2018; Kruk et al., 2019). The relationship between psychological distress and the redox status alteration of the body has been previously shown in several studies using different murine models in the liver, brain, pancreas, kidney, lungs, and heart (Şahin \& Gümüşlü, 2007; Jafari et al., 2014; Mejia-Carmona et al., 2014, 2015; López-López et al., 2016; de Sousa Rodrigues et al., 2017).

In the present study, we focused on the changes induced by distress on liver proteomics. One of the liver functions is the regulation of the redox status. Although the hepatic antioxidant system 
572 is one of the most effective in the body, chronic distress can induce ineffective antioxidant 573 defenses at this level. Our proteomic results showed several changes in proteins involved in the 574 maintenance of redox homeostasis (Table S1). We observed changes induced by the distress in 57519 proteins abundance from a total of 26 proteins described at this level, between them were the 576 enzymes CAT, isoforms of GST, and SOD1. Also, enzyme activity was changed by oxidative 577 stress in the liver, like the increase in GPX activity. This enzyme is involved in modulating 578 cellular oxidant stress and redox-mediated responses (Lubos, Loscalzo \& Handy, 2011). The 579 GPX activity increase is probably due to the need of the cells to scavenge the lipid peroxides 580 formed because of the increase ROS level due to psychological distress (Djordjevic et al., 2011), 581 and piracetam performed its antioxidant function preventing this damage, as previously seen in immune (Grigoruţă et al., 2018) and neuronal cells (Gupta et al., 2014; Verma et al., 2018). In a CUMS rat model, an increase in oxidative proteins and lipids oxidation was observed in the liver after 40 and 60 days of stress (López-López et al., 2016) and, also, five days of psychologically distress exposure altered proteins and lipids level in circulating immune cells (Grigoruţă et al., 2018). These alterations can be due to changes in RE and proteasome pathways involved in the modulation of cell response to high levels of glucocorticoids and catecholamines, as a response to stress (López-López et al., 2016). Moreover, several studies have found that distress promotes lipid peroxidation in the liver and other organs (Demirdaş, Nazıroğlu, \& Ünal, 2016; Duda et al., 2016; López-López et al., 2016). CUMS in male rats induced no changes in the SOD activity in the liver; however, CAT activity was significantly reduced after 20 days of stress (López-López et al., 2016). Besides, a chronic mild stress-induced hepatic oxidative stress model promoted the increase of ROS and lipid peroxidation and the decrease of GPX and CAT activity (Duda et al., 2016). The divergences among the different studies may be due to the type of the psychological stress model, the time of exposure to distress, and the gender-associated differences in response to oxidative stress (Brunelli et al., 2014).

Previous studies showed that piracetam decreases the antioxidant level and therefore decreases the oxidative stress and increases the proinflammatory responses (Singh et al., 2011; Liu et al., 2017; Verma et al., 2018). Moreover, this drug may protect the lipids from cellular membranes against oxidative stress due to its ability to scavenge free radicals, in this way avoiding mitochondrial dysfunction caused by such reactive molecules (Keil et al., 2006; Grigoruță et al., 2018). In the present study, piracetam decreased the GPX and CAT activity in liver in distress conditions (Table 1) due to its ability to reduce the number of oxidant compounds, as observed in blood peripheral immune cells using SR- $\mu$ FTIR (Grigoruță et al., 2018).

However, in non-distressed conditions, possible alterations were shown in circulating mononuclear cells from rats treated with this drug (Grigoruţă et al., 2018). Piracetam has been labeled as a metabolic enhancer as it increases oxygen consumption and mitochondrial activity in stressed neuronal cells (Gupta et al., 2014; Verma et al., 2018). However, little evidence has been found about the effects of this drug on the metabolism under physiological conditions. In previous studies, piracetam has no impact on non-stressed subjects, both on the brain membrane fluidity of young animals (Müller et al., 1997) and cell viability and DNA damage in leukocytes 
612 and macrophages (Singh et al., 2011). In the present study, non-distressed groups showed

613 changes in liver protein abundance and activity under treatment with this drug (Table 1 and S1).

614 Our results suggest that piracetam induces an increase of catabolism rate guided to energy

615 production, which can boost the ROS production and oxidative stress, under physiological

616 conditions. These results support our previous observations made on circulating mononuclear

617 cells from rats under the same distress conditions, in which a modest increase in oxidative stress

618 in the control group (S-P+) was shown by using SR- $\mu$ FTIR analysis (Grigoruţă et al., 2018). In

619 the same way, the high fatty acid degradation observed in the present study can explain the

620 decrease of lipids/proteins ratio reported in the immune cells from non-distressed rats, which

621 confirms that this drug disturbs the metabolism (Grigoruţă et al., 2018). Therefore, the beneficial

622 effect of piracetam seems to be closely related to the presence of oxidative stress (Keil et al.,

623 2006; Verma et al., 2018).

624

625 Non-alcoholic fatty liver disease (NAFLD)

626 Recently, oxidative stress has been considered a factor that contributes to the NAFLD

627 pathogenesis due to its effects on lipid metabolism. ROS overproduction in mitochondrial

628 electron transport chain (ETC) and non-ETC ROS sources, as fatty acid $\beta$-oxidation, appears to

629 contribute to hepatic metabolic diseases (Chen et al., 2020). Lipid peroxidation has been recently

630 proposed as a possible mechanism for NAFLD development and progression because several

631 circulating biomarkers of this process were identified in patients with NAFLD, as well as the

632 presence of lipid peroxidation products (e.g., MDA and 4-HNE) were correlated with various

633 histological features of non-alcoholic steatohepatitis (Chen et al., 2020). However, little evidence

634 had been provided on the possible relationship between NAFLD and psychological distress. In a

635 recent study, the effects of CUMS on metabolism were assessed in a mouse model of diet-

636 induced obesity, and stress was not associated with changes in liver lipid deposition. However, a

637 high-fat high-fructose diet promoted histological changes in the mouse liver that includes

638 microvesicular lipid droplets, ballooning of hepatocytes, and cell infiltration (de Sousa

639 Rodrigues et al. 2017). Our proteomic results may confirm that prolonged exposure to distress

640 can lead to the development of NAFLD.

641 Parkinson's disease (PD) (rno05012) was one of the enriched pathways. PD shares 86 gene

642 entries with the NAFLD according to the KEGG pathway database

643 (https://www.genome.jp/kegg/), which means that PD is associated with the oxidative stress and

644 mitochondrial dysfunction induced by psychological distress (Grigoruţă et al., 2019, 2020), a

645 molecular response that affects also other organs like the liver (López-López et al., 2016). Many

646 proteins could be involved in the NAFLD progression. In this study, 38 proteins were found

647 variable and belonging to the PD pathway, and 17 of these were not included in the NAFLD

648 pathway (Table S2). One of these shared proteins is the PD protein 7 (PARK7) or protein DJ-1,

649 which is a multifunctional protein with transcription modulatory and antioxidant activity, and

650 acts as a cytoprotective in different cellular compartments (Junn et al., 2009). This protein is also

651 required for the maintenance of mitochondrion homeostasis, like mitochondrial morphology and 
652 function, as well as for autophagy of dysfunctional mitochondria (Xiong et al., 2009). Loss of

653 DJ-1 causes impaired mitochondrial respiration, increased intramitochondrial ROS, reduced

654 mitochondrial membrane potential, and mitochondrial morphology alteration (Krebiehl et al.,

655 2010). Moreover, DJ-1 is involved in the regulation of antioxidant gene expression through the

656 Nrf2 transcription factor and of oxidative stress-induced apoptosis and has been related to the

657 pathophysiology of immune and inflammatory diseases (Zhang et al., 2020). However, DJ-1 has

658 an essential role in the progression of liver diseases due to its function in the inflammatory

659 response initiation by modulating ROS generation and the immune response. In this study, DJ-1

660 abundance decreased by $50 \%$ in distress conditions. This observation shows the high use of this

661 protein and the significant oxidative damage in the liver induced by psychological distress. A

662 lower expression of DJ-1 was also found in the prefrontal cortex from rats exposed to the same

663 model of distress (Grigoruţă et al., 2019) and in circulating immune cells from distressed

664 PINK1-KO rats (Grigoruţă et al., 2020). In addition to the altered level of DJ-1, distressed rats

665 showed anxiety, motor disfunction, altered mitochondrial respiration in the brain, and ineffective

666 immune response (Grigoruţă et al., 2019, 2020). However, piracetam increased DJ-1 level in the

667 liver, almost $80 \%$ in non-distressed animals, due to the metabolic enhancer effects of this drug.

668 Nevertheless, a previous study showed that the lack of DJ-1 protected against hepatic steatosis

669 because it enhanced the fatty acid oxidation that decreases the hepatic TG accumulation (Xu et

$670 a l ., 2018)$. Therefore, further studies are necessary for the role of this protein in the NAFLD

671 progression in the liver, including gender-associated differences.

672 The connections of DJ-1 with members of the oxidative phosphorylation cluster have been

673 reported in PD and other neurodegenerative diseases. This protein, along with others, assists the

674 regulation of adequate ROS production in mitochondria by ETC and, therefore, maintains a

675 proper mitochondrial function (Rekatsina et al., 2020). DJ-1 has been also related to the

676 antioxidant enzymes CAT, GST, and SOD2 through the Nrf2 transcription factor, which

677 regulates numerous antioxidant genes, being DJ-1 a positive regulator of Nrf2 (Yan et al., 2015).

678

679

680

\section{ER stress}

681

Distress and piracetam also induced alteration in protein processing in the ER. Both rough and

682 smooth ER are widely developed in hepatocytes. The ER homeostasis alteration triggers the ER

683 stress, which promotes the cumulation of misfolded or unfolded proteins in this organelle. ER

684 stress has been associated with diverse pathophysiological changes, including inflammation, lipogenesis, insulin resistance, and apoptosis, both animal models and human subjects with NAFLD. The ER is also the origin of ROS, but their input into oxidative stress in NAFLD continues to be unclear (Chen et al., 2020). Our results suggest that distress exposure can induce an increase of the machinery to re-fold denatured proteins or to remove them from the ERassociated protein degradation pathway by the proteasome, probably to prevent the ER stress in the liver. In our previous study, the increase of protein denaturation or an abnormal protein aggregation was found in circulating mononuclear cells from stressed rats by SR- $\mu$ FTIR analysis. 
692 in the non-distressed group ( $\mathrm{S}-\mathrm{P}+)$, which was statistically grouped with $\mathrm{S}+\mathrm{P}+$ by principal

693 component analysis (Grigoruţă et al., 2018). The ER stress has been associated with various

694 liver diseases including NAFLD (Lebeaupin et al., 2018). Oxidative stress, lipotoxicity, and

695 local inflammation induce the progression from hepatic steatosis to steatohepatitis and cirrhosis.

696 To fight against cellular stress and inflammation, the UPR is a vital mechanism in patients with

697 non-alcoholic steatohepatitis, especially in the mitochondria, because factors, such as

698 mitochondrial UPR and mitohormesis, prevent the evolution of fatty liver to fibrosis (Solano-

699 Urrusquieta et al., 2020). Previous studies showed that the PPAR signaling pathway (through

700 PPAR $\alpha$ receptor) can assist ER stress by regulating fatty acid $\beta$-oxidation pathways in

701 peroxisomes and mitochondria, and also by inhibiting the inflammatory response in the liver

702 (Wang et al., 2017). This pathway has been shown to mediate hepatic protection and the

703 decrease of hepatocyte apoptosis, by regulating ER stress, in acute liver failure (Zhang et al.,

704 2016). In this study, the PPAR signaling pathway was increased in stressed animals and by

705 piracetam, which can confirm the ER stress.

706

707

\section{Metabolism of xenobiotics by Cyt P450}

708 The biotransformation process involving Phases I and II enzymes of xenobiotics and drug

709 metabolism was also affected by distress in the present study. Similar results were found in a

710 previous study, in which psychological stress alone impacts the regulation of liver proteins

711 involved in Phase I and II, affecting the liver functionality, in a restraint stress mouse model

712 (Flint et al., 2010). In our study, the cytochrome P450 2E1 (CYP2E1) was found more abundant

713 in the rats' liver after exposure to distress. This is one of the most abundant proteins in the liver

714 of stressed rats and has been associated with steatohepatitis development. The functional

715 stabilization of CYP2E1 induced hepatic oxidative stress, JNK1 signaling activation, insulin

716 resistance, and accumulation of fatty acids and triglycerides, which results in liver injury,

717 contributing to non-alcoholic steatohepatitis (Kim et al., 2016). This result supports the

718 relationship between chronic exposure to psychological distress and the progress of NAFLD

719 (Solano-Urrusquieta et al., 2020). In this study, piracetam avoided this change, but altered

720 CYP2E1 expression in the liver of non-distressed rats, probably due to its stimulatory effect on

721 metabolism (Müller et al., 1997; Keil et al., 2006; Kurz et al., 2010; Verma et al., 2018).

722

723

\section{Effect of piracetam on animal behavior}

724

725

Piracetam did not change the rat behavior under five days of exposure to distress, contrary to our previous study where nine days of drug administration diminished the anxiety behavior induced

726

727 by distress (Grigoruţă et al., 2018), probably because a longer period of drug treatment is needed

728 to obtain significant results. However, the drug induced a change in animal conduct when it was

729

730 administered under physiological conditions. This result confirms our previous studies, where piracetam induced neurostimulation and psychomotor agitation in healthy individuals (Corazza

731 et al., 2014; Grigoruță et al., 2018), probably due to its actions as a metabolic enhancer (Müller et al., 1997; Keil et al., 2006; Kurz et al., 2010; Verma et al., 2018). 


\section{Effect of distress and piracetam on biochemical parameters}

734

In the present study, none of the specific markers for liver injury, like ALT and AST, were

735 affected by distress and/or piracetam, although the total bilirubin tended to decrease, regardless

736 of whether rats were exposed or not to distress. Low bilirubin levels have been closely related to

737 cardiovascular diseases or a high risk of cerebral deep white matter lesions (Higuchi et al., 2018). Contrary to our results, CUMS model induced an increase in the activity of ALT and AST in male rats, suggesting liver damage (Jia et al., 2016). Again, gender-associated studies need further investigations. significant increase in BUN level, indicating that the sympathetic system activation by psychological distress stimulates protein degradation, or/and induces hemodynamic changes, that can lead to kidney function failure and increase the risk for cardiovascular disease (Kazory, 2010). Piracetam protected kidney functions by diminishing BUN and urea levels. Previous studies showed the beneficial effect of this drug on microcirculation not only in the brain but also in the periphery (Winblad, 2005).

\section{Conclusions}

In the present study, we verify that our emotional distress paradigm causes changes in proteins

752 involved in redox status homeostasis, ER stress, and the biotransformation processes in the distressed rat liver. These results support the relationship between the distress and the development of NAFLD and non-alcoholic steatohepatitis. We propose new potential targets of interest in liver-related as the antioxidant proteins DJ-1, GPX, PRDX5, GLRX5, TXNDR1, and plasma biochemical parameters as urea and BUN levels related to kidney function for further

756 studies.

758

759

Piracetam appears to counteract the molecular effects caused by distress in the liver, although it has the opposite effect under normal conditions. Thus, we confirmed that piracetam has antioxidant effects on the liver as long as the body is subjected to the molecular effects of

760 psychological distress.

761 On the other hand, the influence of gender in the physiological response to oxidative stress and

762 how this can affect the body and evolve in diverse pathologies should be further studied since

763 females seem to better counteract the effects of distress on the brain, as previously described

764 (Grigoruţă et al., 2019).

765 Finally, these results generate new hypotheses for the molecular mechanism study of how

766 psychological distress affects liver function and new pharmacological applications of known

767 drugs in the whole organism protection.

768

769

\section{Acknowledgements}


770 We are very grateful to Dr. Diana Marcela Beristain-Ruiz from Veterinary Science Department, 771 Biomedicine Science Institute at the UACJ, for her invaluable support in the analysis of the

772 biochemical parameters.

773

774

\section{References}

775

776

777

778

779

780

781

782

783

784

785

786

787

788

789

790

791

792

793

794

795

796

797

798

799

800

801

802

803

804

805

806

807

808

809

810

811

812

813

814

Abdel-Salam OME, Khadrawy YA, Salem NA, Sleem AA. 2011. Oxidative stress in a model of toxic demyelination in rat brain: The effect of piracetam and vinpocetine. Neurochemical Research 36:1062-1072. DOI: 10.1007/s11064-011-0450-1.

Abdel-Salam OME, Salem NA, El-Shamarka ME-S, Ahmed NA-S, Hussein JS, El-Khyat ZA. 2013. Cannabis-induced impairement of learning and memory: Effect of different nootropic drugs. Experimantal and Clinical Sciences Journal 12:193-214.

Adachi S, Kawamura K, Takemoto K. 1993. Oxidative damage of nuclear DNA in liver of rats exposed to psychological stress. Cancer Research 53:4153-4155.

Aebi H. 1984. Catalase in vitro. Methods in Enzymology 105:121-126.

Alkuraishy HM, Algareeb AI, Albuhadilly AK, Almgoter BM. 2014. Modulation effects of piracetam and Ginkgo biloba on the cognitive and working memory functions:

Psychometric study. Journal of Neurology and Neurophysiology 5. DOI: 10.4172/21559562.1000234.

Brunelli E, Domanico F, Russa D, Pellegrino D. 2014. Sex differences in oxidative stress biomarkers. Current Drug Targets. DOI: 10.2174/1389450115666140624112317.

Canteras N, Pavesi E, Carobrez A. 2015. Olfactory instruction for fear: neural system analysis. Frontiers in Neuroscience 9:276.

Chen Z, Tian R, She Z, Cai J, Li H. 2020. Role of oxidative stress in the pathogenesis of nonalcoholic fatty liver disease. Free Radical Biology and Medicine 152:116-141. DOI: https://doi.org/10.1016/j.freeradbiomed.2020.02.025.

Chida Y, Sudo N, Kubo C. 2005. Psychological stress impairs hepatic blood flow via central CRF receptors in mice. Life Sciences 76:1707-1712. DOI: 10.1016/j.lfs.2004.08.032.

Corazza O, Bersani FS, Brunoro R, Valeriani G, Martinotti G, Schifano F. 2014. The diffusion of performance and image-enhancing drugs (PIEDs) on the internet: The abuse of the cognitive enhancer piracetam. Substance Use \& Misuse 49:1-8. DOI: 10.3109/10826084.2014.912232.

Demirdaş A, Nazıroğlu M, Ünal GÖ. 2016. Agomelatine reduces brain, kidney and liver oxidative stress but increases plasma cytokine production in the rats with chronic mild stress-induced depression. Metabolic Brain Disease. DOI: 10.1007/s11011-016-9874-2.

Depke M, Fusch G, Domanska G, Geffers R, Völker U, Schuett C, Kiank C. 2008. Hypermetabolic syndrome as a consequence of repeated psychological stress in mice. Endocrinology 149:2714-2723. DOI: 10.1210/en.2008-0038.

Depke M, Steil L, Domanska G, Völker U, Schütt C, Kiank C. 2009. Altered hepatic mRNA expression of immune response and apoptosis-associated genes after acute and chronic psychological stress in mice. Molecular Immunology 46:3018-3028. DOI: 10.1016/j.molimm.2009.06.014.

Dielenberg RA, McGregor IS. 2001. Defensive behavior in rats towards predatory odors: A review. Neuroscience and Biobehavioral Reviews 25:597-609. DOI: 10.1016/S01497634(01)00044-6.

Djordjevic D, Cubrilo D, MacUra M, Barudzic N, Djuric D, Jakovljevic V. 2011. The influence

Peer) reviewing PDF | (2020:11:55760:1:0:NEW 31 Mar 2021) 
815 of training status on oxidative stress in young male handball players. Molecular and

816 Cellular Biochemistry. DOI: 10.1007/s11010-011-0732-6.

817

818

819

820

821

822

823

824

825

826

827

828

829

830

831

832

833

834

835

836

837

838

839

840

841

842

843

844

845

846

847

848

849

850

851

852

853

854

855

856

857

858

859

860

Dorfer V, Pichler P, Stranzl T, Stadlmann J, Taus T, Winkler S, Mechtler K. 2014. MS Amanda, a universal identification algorithm optimized for high accuracy tandem mass spectra. Journal of Proteome Research. DOI: 10.1021/pr500202e.

Duda W, Curzytek K, Kubera M, Iciek M, Kowalczyk-Pachel D, Bilska-Wilkosz A, LorencKoci E, Leśkiewicz M, Basta-Kaim A, Budziszewska B, Regulska M, Ślusarczyk J, Gruca P, Papp M, Maes M, Lasoń W, Antkiewicz-Michaluk L. 2016. The effect of chronic mild stress and imipramine on the markers of oxidative stress and antioxidant system in rat liver. Neurotoxicity research 30:173-184. DOI: 10.1007/s12640-016-9614-8.

Dumbell R, Matveeva O, Oster H. 2016. Circadian clocks, stress, and immunity. Frontiers in Endocrinology. DOI: 10.3389/fendo.2016.00037.

Eng JK, McCormack AL, Yates JR. 1994. An approach to correlate tandem mass spectral data of peptides with amino acid sequences in a protein database. Journal of the American Society for Mass Spectrometry. DOI: 10.1016/1044-0305(94)80016-2.

Espinosa-Gómez FC, Ruíz-May E, Serio-Silva JC, Chapman CA. 2020. Salivary proteome of a neotropical primate: potential roles in host defense and oral food perception. PeerJ. DOI: 10.7717/peerj.9489.

Flint MS, Hood BL, Sun M, Stewart NA, Jones-Laughner J, Conrads TP. 2010. Proteomic analysis of the murine liver in response to a combined exposure to psychological stress and 7,12-dimethylbenz(a)anthracene. Journal of Proteome Research 9:509-520. DOI: $10.1021 / \mathrm{pr} 900861 \mathrm{j}$.

Furman D, Campisi J, Verdin E, Carrera-Bastos P, Targ S, Franceschi C, Ferrucci L, Gilroy DW, Fasano A, Miller GW, Miller AH, Mantovani A, Weyand CM, Barzilai N, Goronzy JJ, Rando TA, Effros RB, Lucia A, Kleinstreuer N, Slavich GM. 2019. Chronic inflammation in the etiology of disease across the life span. Nature Medicine 25:1822-1832. DOI: 10.1038/s41591-019-0675-0.

González-Fernández R, Aloria K, Valero-Galván J, Redondo I, Arizmendi JM, Jorrín-Novo J V. 2014. Proteomic analysis of mycelium and secretome of different Botrytis cinerea wild-type strains. Journal of Proteomics. DOI: 10.1016/j.jprot.2013.06.022.

Grigoruţă M, Dagda RK., Díaz-Sánchez ÁG., Martínez-Martínez A. 2020. Psychological distress promotes bioenergetics alterations in peripheral blood mononuclear cells of PINK1 knockout rats: Implications to Parkinson's disease. Scientific Reports 10:1-14. DOI: 10.1038/s41598-020-66745-9.

Grigoruţă M, Martínez-Martínez A, Dagda RY, Dagda RK. 2019. Psychological stress phenocopies brain mitochondrial dysfunction and motor deficits as observed in a parkinsonian rat model. Molecular Neurobiology:1-18. DOI: https://doi.org/10.1007/s12035-019-01838-9.

Grigoruţă M, Vargas-Caraveo A, Vázquez-Mayorga E, Castillo-Michel HA, Díaz-Sánchez ÁG, Reyes-Herrera J, Martínez-Martínez A. 2018. Blood mononuclear cells as speculum of emotional stress analyzed by synchrotron infrared spectroscopy and a nootropic drug. Spectrochimica Acta - Part A: Molecular and Biomolecular Spectroscopy 204:475-483. DOI: $10.1016 /$ j.saa.2018.06.075.

Gupta S, Rai G, Bharal N, Mediratta PK, Banerjee BD, Sharma KK. 2009. Reversal of propoxurinduced impairment of step-down passive avoidance, transfer latency and oxidative stress by piracetam and ascorbic acid in rats. Enviornmental Toxicology and Pharmacology

Peer] reviewing PDF | (2020:11:55760:1:0:NEW 31 Mar 2021) 
861

862

863

864

865

866

867

868

869

870

871

872

873

874

875

876

877

878

879

880

881

882

883

884

885

886

887

888

889

890

891

892

893

894

895

896

897

898

899

900

901

902

903

904

905

906
28:403-408. DOI: 10.1016/j.etap.2009.06.007.

Gupta S, Verma DK, Biswas J, Siva Rama Raju K, Joshi N, Wahajuddin, Singh S. 2014. The metabolic enhancer piracetam attenuates mitochondrion-specific endonuclease $\mathrm{G}$ translocation and oxidative DNA fragmentation. Free Radical Biology and Medicine 73:278-290. DOI: 10.1016/J.FREERADBIOMED.2014.05.014.

Guy J, Peters MG. 2013. Liver disease in women: The influence of gender on epidemiology, natural history, and patient outcomes. Gastroenterology and Hepatology 9:633-639.

Habig WH, Pabst MJ, Jakoby WB. 1974. Glutathione S-transferases: the first enzymatic step in mercapturic acid formation. The Journal of Biological Chemistry 249:7130-7139.

Hackett RA, Steptoe A. 2017. Type 2 diabetes mellitus and psychological stress - a modifiable risk factor. Nature Reviews Endocrinology 13:547-560. DOI: 10.1038/nrendo.2017.64.

Hanamsagar R, Bilbo SD. 2016. Sex differences in neurodevelopmental and neurodegenerative disorders: Focus on microglial function and neuroinflammation during development. The Journal of Steroid Biochemistry and Molecular Biology 1160:127-133. DOI: 10.1016/j.jsbmb.2015.09.039.Sex.

Higuchi S, Kabeya Y, Uchida J, Kato K, Tsukada N. 2018. Low bilirubin levels indicate a high risk of cerebral deep white matter lesions in apparently healthy subjects. Scientific Reports 8:6473. DOI: 10.1038/s41598-018-24917-8.

Hodes GE, Kana V, Menard C, Merad M, Russo SJ. 2015. Neuroimmune mechanisms of depression. Nature Neuroscience 18:1386-1393. DOI: 10.1038/nn.4113.

Holinski S, Claus B, Alaaraj N, Dohmen MP, Kirilova K, Neumann K, Uebelhack R, Konertz W. 2008. Cerebroprotective effect of piracetam in patients undergoing coronary bypass surgery. Medical Science Monitor 14:53-57.

Jafari M, Salehi M, Zardooz H, Rostamkhani F. 2014. Response of liver antioxidant defense system to acute and chronic physical and psychological stresses in male rats. Experimantal and Clinical Sciences Journal 13:161-171. DOI: 10.17877/DE290R-1067.

Jia HM, Li Q, Zhou C, Yu M, Yang Y, Zhang HW, Ding G, Shang H, Zou ZM. 2016. Chronic unpredictive mild stress leads to altered hepatic metabolic profile and gene expression. Scientific Reports 6. DOI: 10.1038/srep23441.

Junn E, Jang WH, Zhao X, Jeong BS, Mouradian MM. 2009. Mitochondrial localization of DJ-1 leads to enhanced neuroprotection. Journal of Neuroscience Research 87:123-129. DOI: 10.1002/jnr.21831.

Kazory A. 2010. Emergence of blood urea nitrogen as a biomarker of neurohormonal activation in heart failure. American Journal of Cardiology 106:694-700. DOI: 10.1016/j.amjcard.2010.04.024.

Keil U, Scherping I, Hauptmann S, Schuessel K, Eckert A, Mu WE. 2006. Piracetam improves mitochondrial dysfunction following oxidative stress. British Journal of Pharmacology 147:199-208. DOI: 10.1038/sj.bjp.0706459.

Kessler J, Thiel A, Karbe H, Heiss WD. 2000. Piracetam improves activated blood flow and facilitates rehabilitation of poststroke aphasic patients. Stroke:2112-2117.

Kim S-M, Grenert JP, Patterson C, Correia MA. 2016. CHIP(-/-)-mouse liver: adiponectinAMPK-FOXO-activation overrides CYP2E1-elicited JNK1-activation, delaying onset of NASH: Therapeutic implications. Scientific Reports 6:29423. DOI: 10.1038/srep29423.

Kinlein SA, Karatsoreos IN. 2019. The hypothalamic-pituitary-adrenal axis as a substrate for stress resilience: Interactions with the circadian clock. Frontiers in Neuroendocrinology:100819. DOI: 10.1016/J.YFRNE.2019.100819.

Peer] reviewing PDF | (2020:11:55760:1:0:NEW 31 Mar 2021) 
907

908

909

910

911

912

913

914

915

916

917

918

919

920

921

922

923

924

925

926

927

928

929

930

931

932

933

934

935

936

937

938

939

940

941

942

943

944

945

946

947

948

949

950

951

952

Kosta P, Mehta AK, Sharma AK, Khanna N, Mediratta PK, Mundhada DR, Suke S. 2011. Effect of piracetam and vitamin $\mathrm{E}$ on phosphamidon-induced impairment of memory and oxidative stress in rats. Human and Experimental Toxicology 30:1626-1634. DOI: 10.3109/01480545.2011.649093.

Krebiehl G, Ruckerbauer S, Burbulla LF, Kieper N, Maurer B, Waak J, Wolburg H, Gizatullina Z, Gellerich FN, Woitalla D, Riess O, Kahle PJ, Proikas-Cezanne T, Krüger R. 2010. Reduced basal autophagy and impaired mitochondrial dynamics due to loss of Parkinson's disease-associated protein DJ-1. PloS one 5:e9367-e9367. DOI: 10.1371/journal.pone.0009367.

Krok K, Koteish A. 2010. Liver Disease in Women. In: Principles of Gender-Specific Medicine. Elsevier Inc., 331-344. DOI: 10.1016/B978-0-12-374271-1.00031-9.

Kruk J, Aboul-Enein BH, Bernstein J, Gronostaj M. 2019. Psychological stress and cellular aging in cancer: A meta-analysis. Oxidative Medicine and Cellular Longevity 2019:1270397. DOI: 10.1155/2019/1270397.

Kurz C, Ungerer I, Lipka U, Kirr S, Eckert A, Leuner K. 2010. The metabolic enhancer piracetam ameliorates the impairment of mitochondrial function and neurite outgrowth induced by ß-amyloid peptide. British journal of pharmacology 160:246-257. DOI: 10.1111/j.1476-5381.2010.00656.x.

Lebeaupin C, Vallée D, Hazari Y, Hetz C, Chevet E, Bailly-Maitre B. 2018. Endoplasmic reticulum stress signalling and the pathogenesis of non-alcoholic fatty liver disease. Journal of Hepatology. DOI: 10.1016/j.jhep.2018.06.008.

Leuner K, Kurz C, Guidetti G, Orgogozo J-M, Muller WE. 2010. Improved mitochondrial function in brain aging and Alzheimer disease - the new mechanism of action of the old metabolic enhancer piracetam. Frontiers in Neuroscience 4:1-11. DOI: 10.3389/fnins.2010.00044.

Liu Z, Zhou T, Ziegler AC, Dimitrion P, Zuo L. 2017. Oxidative stress in neurodegenerative diseases: from molecular mechanisms to clinical applications. Oxidative Medicine and Cellular Longevity 2017:1-11. DOI: 10.1155/2017/2525967.

López-López AL, Bonilla HJ, Escobar Villanueva M del C, Brianza MP, Vázquez GP, Alarcón FJA. 2016. Chronic unpredictable mild stress generates oxidative stress and systemic inflammation in rats. Physiology and Behavior. DOI: 10.1016/j.physbeh.2016.03.017.

Lubos E, Loscalzo J, Handy DE. 2011. Glutathione peroxidase-1 in health and disease: From molecular mechanisms to therapeutic opportunities. Antioxidants and Redox Signaling 15:1957-1997. DOI: 10.1089/ars.2010.3586.

Malykh AG, Sadaie MR. 2010. Piracetam and piracetam-like drugs. Drugs 70:287-312. DOI: 10.2165/11319230-000000000-00000.

Marklund S, Marklund G. 1974. Involvement of the superoxide anion radical in the autoxidation of pyrogallol and a convenient assay for superoxide dismutase. European Journal of Biochemistry 47:469-474. DOI: 10.1111/j.1432-1033.1974.tb03714.x.

Mejia-Carmona GE, Gosselink KL, de la Rosa L a., Pérez-Ishiwara G, Martínez-Martínez A. 2014. Evaluation of antioxidant enzymes in response to predator odor stress in prefrontal cortex and amygdala. Neurochemical Journal 8:125-128. DOI: 10.1134/S181971241402007X.

Mejia-Carmona GE, Gosselink KL, Pérez-Ishiwara G, Martínez-Martínez A. 2015. Oxidant/antioxidant effects of chronic exposure to predator odor in prefrontal cortex, amygdala, and hypothalamus. Molecular and Cellular Biochemistry 406:121-129. DOI: 
953

954

955

956

957

958

959

960

961

962

963

964

965

966

967

968

969

970

971

972

973

974

975

976

977

978

979

980

981

982

983

984

985

986

987

988

989

990

991

992

993

994

995

996

997

998

10.1007/s11010-015-2430-2.

Muley MM, Thakare VN, Patil RR, Bafna PA, Naik SR. 2013. Amelioration of cognitive, motor, endogenous defense functions with silymarin, piracetam and protocatechuic acid in the cerebral global ischemic rat model. Life Sciences 93:51-57. DOI: 10.1016/j.lfs.2013.05.020.

Müller WE, Koch S, Scheuer K, Rostock A, Bartsch R. 1997. Effects of piracetam on membrane fluidity in the aged mouse, rat, and human brain. Biochemical Pharmacology 53:135-140. DOI: $10.1016 / \mathrm{S} 0006-2952(96) 00463-7$.

Pandey S, Garabadu D. 2016. Piracetam facilitates the anti-amnesic but not anti-diabetic activity of metformin in experimentally induced type-2 diabetic encephalopathic rats. Cellular and Molecular Neurobiology. DOI: 10.1007/s10571-016-0418-4.

Rekatsina M, Paladini A, Piroli A, Zis P, Pergolizzi J V, Varrassi G. 2020. Pathophysiology and therapeutic perspectives of oxidative stress and neurodegenerative diseases: A narrative review. Advances in Therapy 37:113-139. DOI: 10.1007/s12325-019-01148-5.

Russ TC, Kivimäki M, Morling JR, Starr JM, Stamatakis E, Batty GD. 2015. Association between psychological distress and liver disease mortality: A meta-analysis of individual study participants. Gastroenterology 148:958-966. DOI: 10.1053/j.gastro.2015.02.004.

Şahin E, Gümüşlü S. 2007. Immobilization stress in rat tissues: Alterations in protein oxidation, lipid peroxidation and antioxidant defense system. Comparative Biochemistry and Physiology - C Toxicology and Pharmacology. DOI: 10.1016/j.cbpc.2006.10.009.

Schiavone S, Jaquet V, Trabace L, Krause KH. 2013. Severe life stress and oxidative stress in the brain: From animal models to human pathology. Antioxidants and Redox Signaling 18:1475-1490. DOI: $10.1089 /$ ars.2012.4720.

du Sert NP, Ahluwalia A, Alam S, Avey MT, Baker M, Browne WJ, Clark A, Cuthill IC, Dirnagl U, Emerson M, Garner P, Holgate ST, Howells DW, Hurst V, Karp NA, Lazic SE, Lidster K, MacCallum CJ, Macleod M, Pearl EJ, Petersen OH, Rawle F, Reynolds P, Rooney K, Sena ES, Silberberg SD, Steckler T, Würbel H. 2020. Reporting animal research: Explanation and elaboration for the arrive guidelines 2.0. PLoS Biology. DOI: 10.1371/journal.pbio.3000411.

Sharif K, Watad A, Coplan L, Lichtbroun B, Krosser A, Lichtbroun M, Bragazzi NL, Amital H, Afek A, Shoenfeld Y. 2018. The role of stress in the mosaic of autoimmunity: An overlooked association. Autoimmunity Reviews 17:967-983. DOI: 10.1016/J.AUTREV.2018.04.005.

Shinoda K, Tomita M, Ishihama Y. 2009. emPAI Calc — for the estimation of protein abundance from large-scale identification data by liquid chromatography-tandem mass spectrometry. Bioinformatics 26:576-577. DOI: 10.1093/bioinformatics/btp700.

Shrestha S, Singh M, Shrestha U, Mishra A. 2014. Palliative effect of piracetam on valproate induced liver injury. Research Journal of Pharmaceutical, Biological and Chemical Sciences 5:260-267.

Singh S, Goswami P, Swarnkar S, Singh SP, Wahajuddin, Nath C, Sharma S. 2011. A study to evaluate the effect of nootropic drug-piracetam on DNA damage in leukocytes and macrophages. Mutation research 726:66-74. DOI: 10.1016/j.mrgentox.2011.08.009.

Singhal SS, Singh SP, Singhal P, Horne D, Singhal J, Awasthi S. 2015. Antioxidant role of glutathione S-transferases: 4-Hydroxynonenal, a key molecule in stress-mediated signaling. Toxicology and Applied Pharmacology. DOI: 10.1016/j.taap.2015.10.006.

Solano-Urrusquieta A, Morales-González JA, Castro-Narro GE, Cerda-Reyes E, Flores-Rangel PD, Fierros-Oceguera R. 2020. NRF-2 and nonalcoholic fatty liver disease. Annals of

Peer) reviewing PDF | (2020:11:55760:1:0:NEW 31 Mar 2021) 
999

1000

1001

1002

1003

1004

1005

1006

1007

1008

1009

1010

1011

1012

1013

1014

1015

1016

1017

1018

1019

1020

1021

1022

1023

1024

1025

1026

1027

1028

1029

1030

1031

1032

1033

1034

1035

1036

1037

1038

1039

1040

1041

1042

1043

1044

Hepatology. DOI: 10.1016/J.AOHEP.2019.11.010.

de Sousa Rodrigues ME, Bekhbat M, Houser MC, Chang J, Walker DI, Jones DP, Oller do Nascimento CMP, Barnum CJ, Tansey MG. 2017. Chronic psychological stress and highfat high-fructose diet disrupt metabolic and inflammatory gene networks in the brain, liver, and gut and promote behavioral deficits in mice. Brain, Behavior, and Immunity. DOI: 10.1016/j.bbi.2016.08.021.

Srivastava S, Boyer JL. 2010. Psychological stress is associatedwith relapse in type 1 autoimmune hepatitis. Liver International 30:1439-1447. DOI: 10.1111/j.14783231.2010.02333.x.

Swain MG. 2000. Stress and the gastrointestinal tract. I. Stress and hepatic inflammation. American Journal of Physiology - Gastrointestinal and Liver Physiology 279:1135-1138.

Szklarczyk D, Gable AL, Lyon D, Junge A, Wyder S, Huerta-Cepas J, Simonovic M, Doncheva NT, Morris JH, Bork P, Jensen LJ, Mering C von. 2019. STRING v11: protein-protein association networks with increased coverage, supporting functional discovery in genomewide experimental datasets. Nucleic acids research 47:D607-D613. DOI: 10.1093/nar/gky1131.

Vargas-Caraveo A, Pérez-Ishiwara DG, Martínez-Martínez A. 2015. Chronic psychological distress as an inducer of microglial activation and leukocyte recruitment into the area postrema. Neuroimmunomodulation 22:311-321. DOI: 10.1159/000369350.

Verma DK, Gupta S, Biswas J, Joshi N, Singh A, Gupta P, Tiwari S, Sivarama Raju K, Chaturvedi S, Wahajuddin M, Singh S. 2018. New therapeutic activity of metabolic enhancer piracetam in treatment of neurodegenerative disease: Participation of caspase independent death factors, oxidative stress, inflammatory responses and apoptosis. Biochimica et Biophysica Acta - Molecular Basis of Disease 1864:2078-2096. DOI: 10.1016/j.bbadis.2018.03.014.

Wadhwa R, Maurya RG and PK. 2018. Oxidative stress and accelerated aging in neurodegenerative and neuropsychiatric disorder. Current Pharmaceutical Design 24:47114725. DOI: http://dx.doi.org/10.2174/1381612825666190115121018.

Wang N, Kong R, Luo H, Xu X, Lu J. 2017. Peroxisome proliferator-activated receptors associated with nonalcoholic fatty liver disease. PPAR Research. DOI: $10.1155 / 2017 / 6561701$.

Wang Y, Li F, Chen X. 2016. Piracetam prevents memory de fi cit induced by postnatal propofol exposure in mice. European Journal of Pharmacology 779:59-65. DOI:

10.1016/j.ejphar.2016.03.013.

Weiss C, Maker HS, Lehrer GM. 1980. Sensitive fluorometric assays for glutathione peroxidase and reductase. Analytical Biochemistry 106:512-516. DOI: 10.1016/0003-2697(80)905564.

Westley K V, August KJ, Alger MR, Markey CH. 2021. Main and interactive effects of diabetes distress and stress from life events on overall psychological distress. Journal of Health Psychology 26:312-318. DOI: 10.1177/1359105318804865.

Winblad B. 2005. Piracetam: A review of pharmacological properties and clinical uses. CNS Drugs Reviews 11:169-182.

Wu Y, Tang J, Zhou C, Zhao L, Chen J, Zeng L, Rao C, Shi H, Liao L, Liang Z, Yang Y, Zhou J, Xie P. 2016. Quantitative proteomics analysis of the liver reveals immune regulation and lipid metabolism dysregulation in a mouse model of depression. Behavioural Brain Research 311:330-339. DOI: 10.1016/j.bbr.2016.05.057. 
1045 Xiong H, Wang D, Chen L, Choo YS, Ma H, Tang C, Xia K, Jiang W, Ronai Z, Zhuang X,

1046

1047

1048

1049

1050

1051

1052

1053

1054

1055

1056

1057

1058

1059

1060

1061

1062

1063

1064

1065

1066

1067

1068

1069

1070

1071

1072 Zhang Z. 2009. Parkin, PINK1, and DJ-1 form a ubiquitin E3 ligase complex promoting unfolded protein degradation. The Journal of clinical investigation 119:650-660. DOI: 10.1172/JCI37617.

Xu M, Wu H, Li M, Wen Y, Yu C, Xia L, Xia Q, Kong X. 2018. DJ-1 deficiency protects hepatic steatosis by enhancing fatty acid oxidation in mice. International Journal of Biological Sciences. DOI: 10.7150/ijbs.28620.

Yan Y-F, Yang W-J, Xu Q, Chen H-P, Huang X-S, Qiu L-Y, Liao Z-P, Huang Q-R. 2015. DJ-1 upregulates anti-oxidant enzymes and attenuates hypoxia/re-oxygenation-induced oxidative stress by activation of the nuclear factor erythroid 2-like 2 signaling pathway. Molecular Medicine Reports 12:4734-4742. DOI: 10.3892/mmr.2015.3947.

Yang L, Zhao M, Magnussen CG, Veeranki SP, Xi B. 2020. Psychological distress and mortality among US adults: Prospective cohort study of 330367 individuals. Journal of Epidemiology and Community Health 74:384-390. DOI: 10.1136/jech-2019-213144.

Zhang L, Ren F, Zhang X, Wang X, Shi H, Zhou L, Zheng S, Chen Y, Chen D, Li L, Zhao C, Duan Z. 2016. Peroxisome proliferator-activated receptor alpha acts as a mediator of endoplasmic reticulum stress-induced hepatocyte apoptosis in acute liver failure. Disease Models and Mechanisms. DOI: 10.1242/dmm.023242.

Zhang L, Wang J, Wang J, Yang B, He Q, Weng Q. 2020. Role of DJ-1 in immune and inflammatory diseases. Frontiers in Immunology 11:994.

Zhao Y, Wu S, Gao X, Zhang Z, Gong J, Zhan R, Wang X, Wang W, Qian L. 2013. Inhibition of cystathionine $\beta$-synthase is associated with glucocorticoids over-secretion in psychological stress-induced hyperhomocystinemia rat liver. Cell Stress and Chaperones 18:631-641. DOI: 10.1007/s12192-013-0416-0.

Zhou Y, Zhou B, Pache L, Chang M, Khodabakhshi AH, Tanaseichuk O, Benner C, Chanda SK. 2019. Metascape provides a biologist-oriented resource for the analysis of systems-level datasets. Nature communications 10:1523. DOI: 10.1038/s41467-019-09234-6.

PeerJ reviewing PDF | (2020:11:55760:1:0:NEW 31 Mar 2021) 


\section{Figure 1}

Classification of proteins identified in the rat liver in each treatment by GeLC-MS/MS.

(A) Venn diagram comparing the number of proteins detected with at least two unique peptides for all experimental groups and the relationship between them. A total of 554 proteins were detected in the four experimental groups. However, 18, 35, 42, and 17 proteins were unique in $\mathrm{S}-\mathrm{P}-, \mathrm{S}-\mathrm{P}+, \mathrm{S}+\mathrm{P}-$, and $\mathrm{S}+\mathrm{P}+$, respectively. (B) $\mathrm{GO}$ analysis representing the subcellular localization of identified proteins performed using STRING webtool. Most of the detected proteins in the four experimental groups were located within membrane, cytosol, mitochondria, and nucleus. Protein number is referred to as the count in a gene set, in this case, in the GO-term. S-P-, rats neither exposed to stress nor with piracetam treatment; $\mathrm{S}-\mathrm{P}+$, rats not exposed to stress but treated with piracetam; $\mathrm{S}+\mathrm{P}-$, rats exposed to stress without piracetam treatment; $\mathrm{S}+\mathrm{P}+$, rats exposed to stress and treated with piracetam.

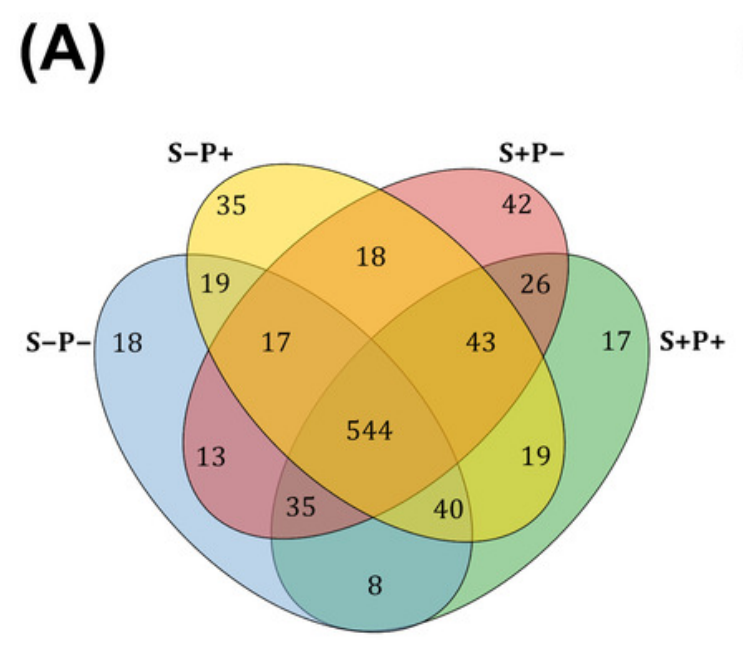

(B)

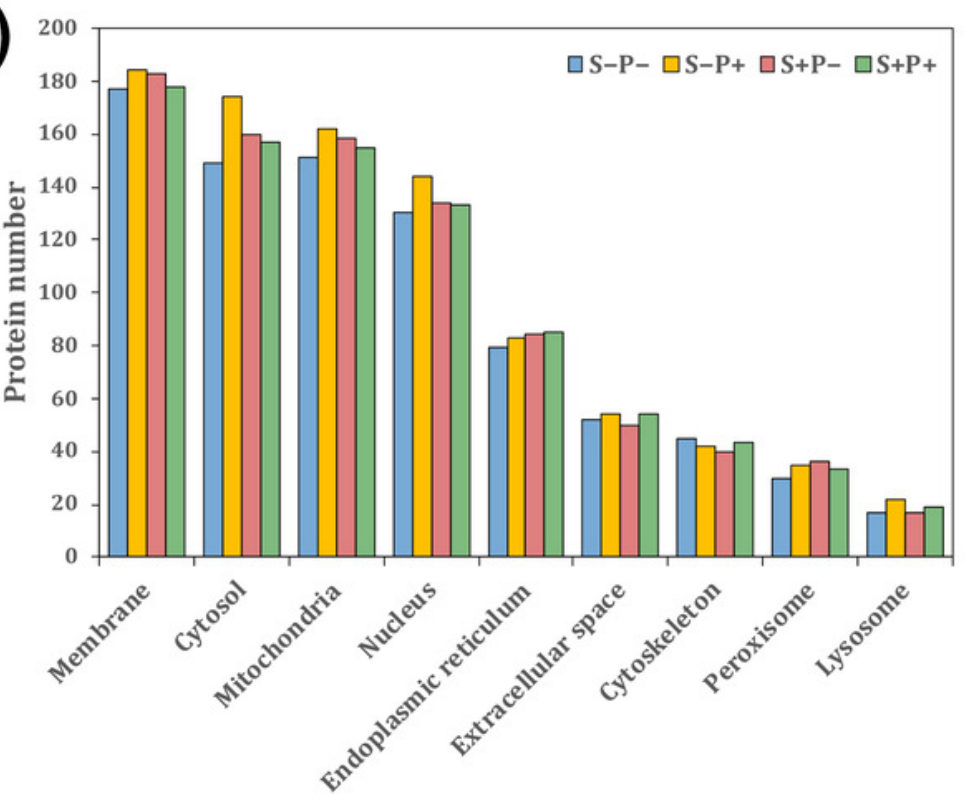




\section{Figure 2}

Pathway enrichment analysis of altered proteins in the liver of rats exposed to distress and piracetam.

The vertical axis indicates the top significant terms in KEGG pathway enrichment analysis of the most and less abundant proteins from (A) $\mathrm{S}+\mathrm{P}-$ compared to $\mathrm{S}-\mathrm{P}-$, (B) $\mathrm{S}+\mathrm{P}+$ compared to $\mathrm{S}+\mathrm{P}-$, and $(\mathrm{C}) \mathrm{S}-\mathrm{P}+$ compared to $\mathrm{S}-\mathrm{P}-$. Proteins related to amino acids metabolism, glucose oxidation, fatty acid mobilization and degradation, protein folding, trafficking and degradation, metabolism of xenobiotics by cytochrome P450, GSH metabolism, antioxidant defense mechanisms, and non-alcoholic fatty acid liver, among others, were highly affected in distress $(\mathrm{S}+\mathrm{P}-)$ when compared to the control group $(\mathrm{S}-\mathrm{P}-)$. Piracetam reverted the changes in metabolism caused by distress. Piracetam administration to non-distressed rats $(\mathrm{S}-\mathrm{P}+)$ induced changes in proteins involved in amino acid, glucose, and fatty acid metabolism, as well as in the metabolism of GSH and xenobiotics by cytochrome P450, among others, compared to the control group (S-P-). Proteins that showed a 1.5-fold change in their relative abundance were considered for the analysis. The analysis was made using Metascape resource, providing the significantly enriched KEGG pathway terms across input protein lists (- $\log 10$ p-value; horizontal axis). 
(A)

Glyoxylate and dicarboxylate metabolism Glycine, serine and threonine metabolism
tabolism of xenobiotics by cytochrome P450 Valine, leucine and isoleucine degradatio Proteasome Peroxisome

Biosynthesis of amino acids

Ascorbate and aldarate metabolism Citrate cycle (TCA cycle)
Parkinson's disease Fatty acid degradation
Retinol metabolism Oxidative phosphorylatio Protein processing in endoplasmic reticulum Alanine, aspartate and glutamate metabolism Pyruvate metabolisn

Non-alcoholic fatty liver disease (NAFLD) Tyrosine metabolism Glutathione metabolism

Arginine and proline metabolism Histidine metabolisn
ry bile acid biosynthesis

One carbon pool by folat One carbon pool by folate
PPAR signaling pathway

Cysteine and methionine metabolism

Leukocyte transendothelial migration Lysine degradation Purine metabolism

Biosynthesis of unsaturated fatty acids Glycerolipid metabolism

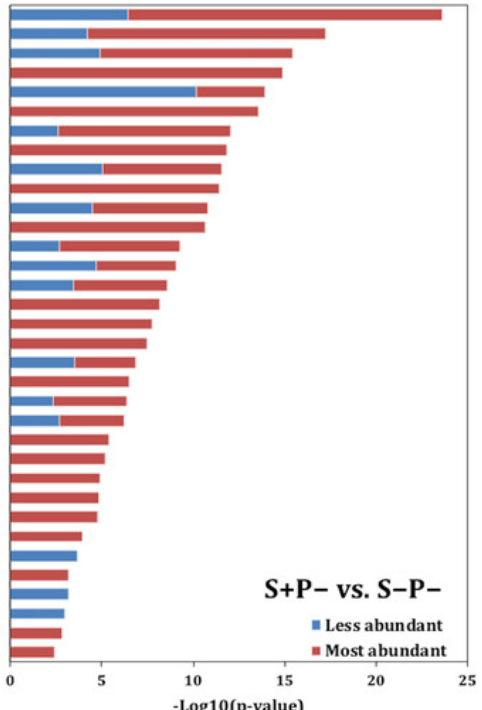

(B)

Metabolism of xenobiotics by cytochrome P450 Ascorbate and aldarate metabolism Glyoxylate and dicarboxylate metabolism Arginine and proline metabolism Valine, leucine and isoleucine degradation Glycine, serine and threonine metabolism Alanine, aspartate and glutamate metabolism Glutathione metabolism
Parkinson's disease Peroxisome Tyrosine metabolism beta-Alanime metabolism One carbon pool by folate Pyruvate metabolism Tryptophan metabolism Histidine metabolism Fatty acid degradation
Fatty acid metabolism Protein processing in endoplasmic reticulum Glycolysis / Gluconeogenesis Oxidative phosphinesis Steroid biosynthesis Arginine biosynthesis Leukocyte transendothelial Complement and coagulation cascades
Nonalcoholic fatty liver disease (NAFLD) PPAR signaling pathway
psynthesis of amino acids Biosynthesis of amino acids
Pentose phosphate pathway Pentose phosphate pathway Citrate cycle (TCA cycle)

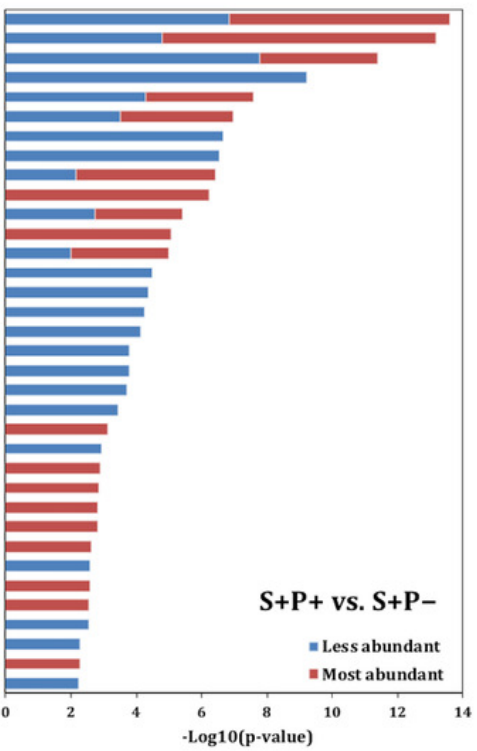

(C)

tabolism of xenobiotics by cytochrome P450 Valine, leucine and isoleucine degradation
Glycine, serine and threonine metabolism Alanine, aspartate and glutamate metabolism Glyoxylate and dicarboxylate metabolism Arginine biosynthesis

Cysteine and methionine metabolism
Biosynthesis of amino acids Fatty acid degradation Parkinson's disease Porphyrin metabolise oxidative phosphorylation Oxidative phosphorylation Ascorbate and aldarate metabolism One carbon pool by folate Glutathione metabolisn Tyrosine metabolism
PPAR signaling pathway Citrate cycle (TCA cycle) Proteasome

Tryptophan metabolism proline metabolis Pyruvate metabolis Butanoate metabolis entose phosphate pathway

enylalanine metabolisin Histidine metabolis Primarybile acid biosynthesis Sulfur moltalis ysine degradation Lysine degradatio

Leukocyte transendothelial migration
Pantothenate and CoA biosynthesis Pantothenate and CoA biosynthes

Regulation of actin cytoskeleto
Propanoate metabolis Fructose and mannose metabolis Andistear stress and atherosclerosis

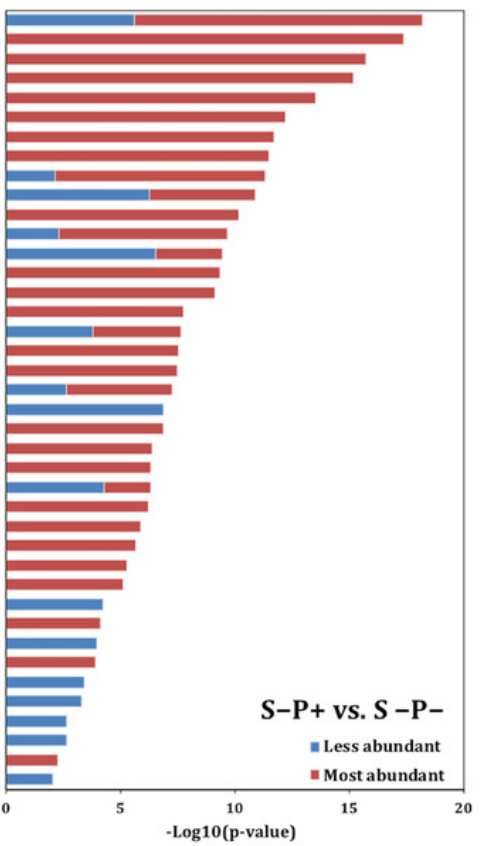

PeerJ reviewing PDF | (2020:11:55760:1:0:NEW 31 Mar 2021) 


\section{Figure 3}

Interaction network of selected proteins with changes in their abundance in the liver of rats exposed to distress and piracetam.

Proteins involved in redox metabolism, GSH metabolism, PD, NAFLD, PPAR signaling pathway, protein processing in ER, metabolism of xenobiotics by Cyt P450, and apoptosis were grouped into sixteen clusters using STRING database. The protein interaction network showed a close relationship among these pathways. Clusters were grouped into five sets distributed around a central group with proteins involved in redox status homeostasis. Edges represent protein-protein associations made using STRING database with a medium confidence level (0.4). Protein clustering was carried out by the Markov Cluster Algorithm $(M C L)$ with a specific inflation parameter of 3 . The different colors in circles indicate diverse clusters. Solid lines represent protein interactions that belong to the same cluster. Dashed lines represent protein interactions belonging to a distinct cluster. The line thickness shows the strength of evidence, with thicker connections presenting higher confidence in the protein-protein interaction (the detailed description of the clusters is shown in Table S4). The colored ellipses show the regrouping of the closest clusters. 


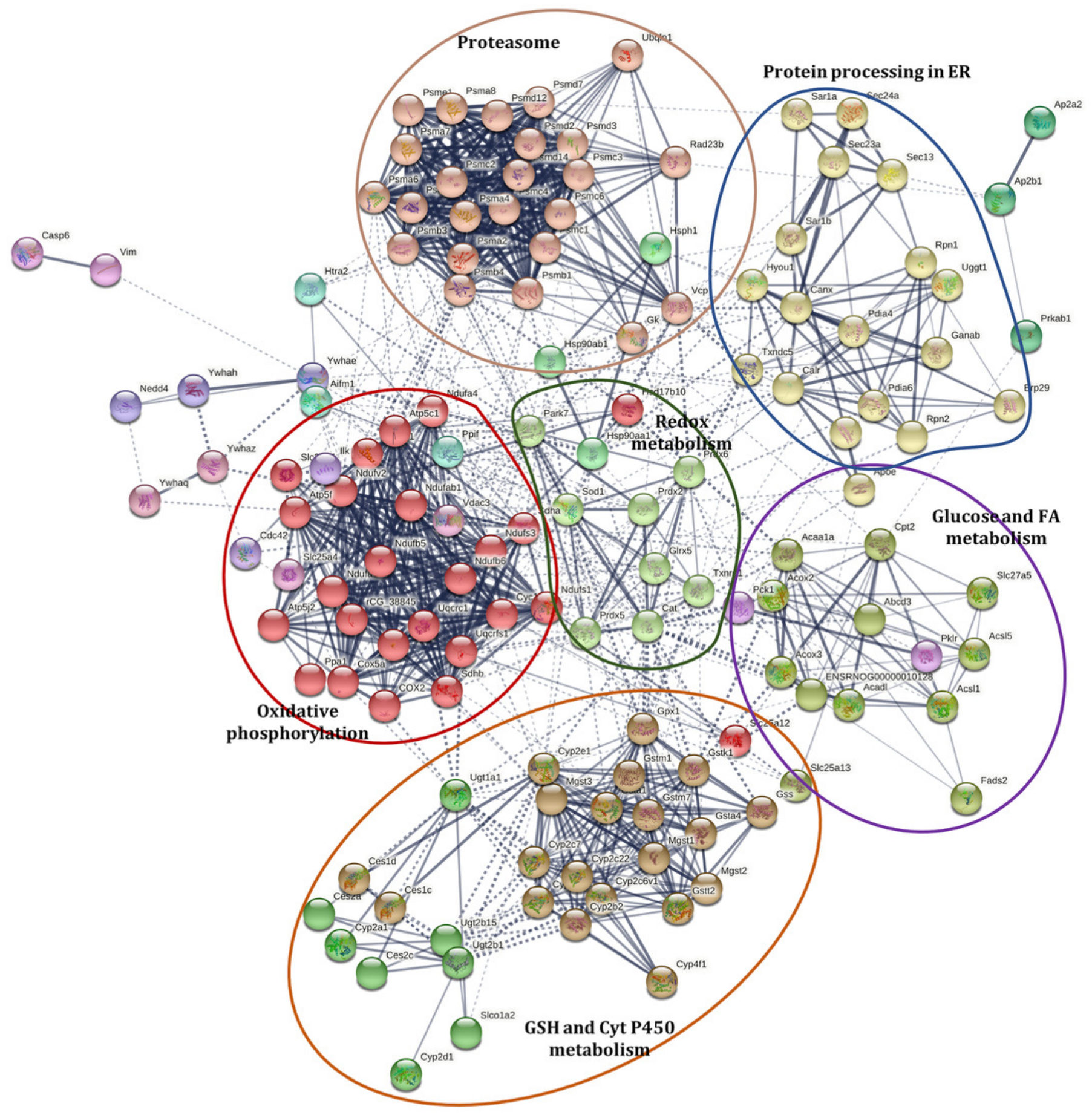




\section{Figure 4}

Effect of chronic psychological distress and piracetam in rat behavior.

(A) Time spent hiding (Hide); (B) time spent in the entrance of the hiding place (Head-out);

(C) time spent exploring the opened part of the box (Exploration); (D) time spent examining the cloth piece permeated (or not) with cat odor (Approach). Rats were exposed to cat odor as a stressor for five consecutive days. Distressed rats $(\mathrm{S}+\mathrm{P}+)$ were in the hiding place during almost all the time of the distress exposure in all five days comparing to the nondistress animals (S-P-), that spent more time exploring the open place, in head out position, and approaching the cloth, from the second day. Piracetam did not change the behavior in distressed rats $(\mathrm{S}+\mathrm{P}+)$, but in non-distressed rats $(\mathrm{S}-\mathrm{P}+)$, the drug provoked an increase in the time spent in the concealment, and a decrease in the time used to explore, to approach the cloth and to be in the alert. $\mathrm{S}-\mathrm{P}-$, rats neither exposed to stress nor with piracetam treatment; $\mathrm{S}-\mathrm{P}+$, rats not exposed to stress but treated with piracetam; $\mathrm{S}+\mathrm{P}-$, rats exposed to stress without piracetam treatment; $\mathrm{S}+\mathrm{P}+$, rats exposed to stress and treated with piracetam. Data are shown as mean \pm S.E.M. ( $n=5$ / group). 
(A)

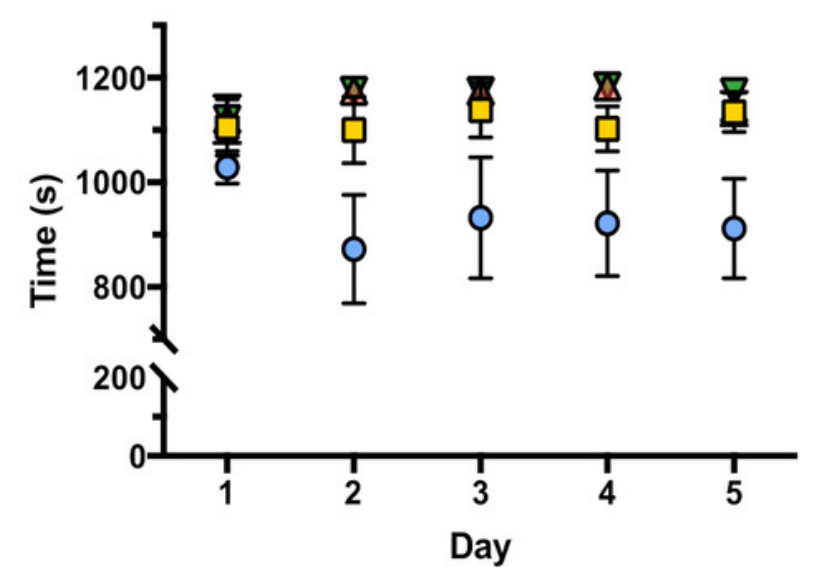

(C)

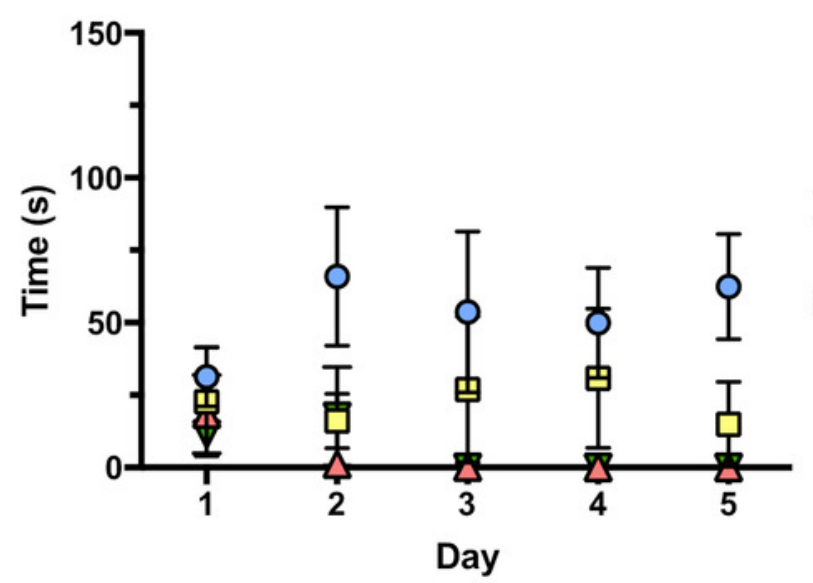

(B) Head-out

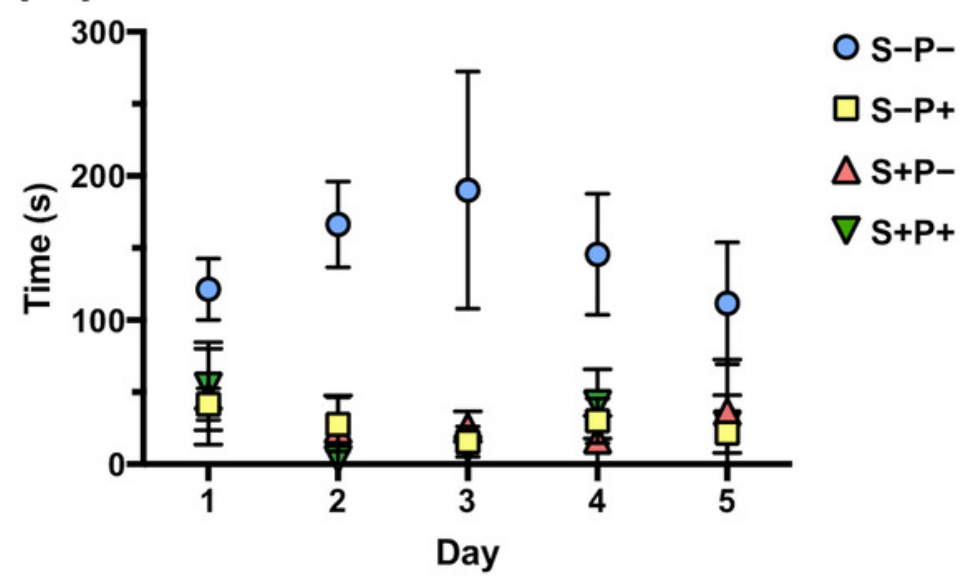

(D)

Approach

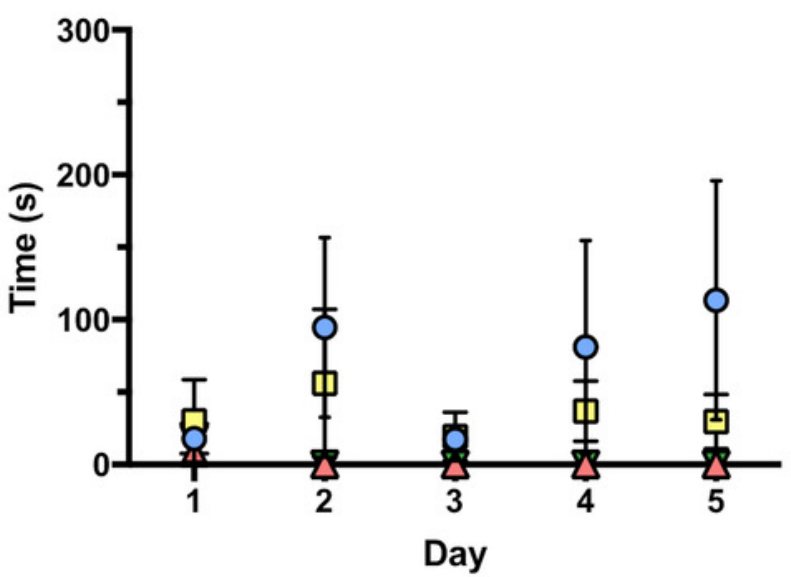




\section{Table $\mathbf{1}$ (on next page)}

Activity measure of redox enzymes expressed as IU per mg of fresh liver weight (FLW) in each experimental group.

Data are represented as mean \pm S.E.M. ( $n=3-5$ / group). Different letters mean significative differences (ANOVA, $p \leq 0.05$ ). CAT: catalase; GR: glutathione reductase; GPX: glutathione peroxidase; GST: glutathione S-transferase; SOD: superoxide dismutase; SOD1: Cu,Zn-SOD, cytosolic; SOD2: Mn-SOD, mitochondrial; S-P-, rats neither exposed to stress nor with piracetam treatment; $\mathrm{S}-\mathrm{P}+$, rats not exposed to stress but treated with piracetam; $\mathrm{S}+\mathrm{P}-$, rats exposed to stress without piracetam treatment; $\mathrm{S}+\mathrm{P}+$, rats exposed to stress and treated with piracetam. 


\begin{tabular}{lccccc}
\hline $\begin{array}{l}\text { Enzyme activity } \\
\text { (IU/mg LFW) }\end{array}$ & $\mathbf{S}-\mathbf{P}-$ & $\mathbf{S}-\mathbf{P}+$ & $\mathbf{S}+\mathbf{P}-$ & $\mathbf{S}+\mathbf{P}+$ & p-value \\
\hline CAT $\left(x 10^{6}\right)$ & $221.6 \pm 19.7^{\mathrm{c}}$ & $167.1 \pm 9.6^{\mathrm{a}}$ & $228.5 \pm 27.0^{\mathrm{c}}$ & $182.4 \pm 14.8^{\mathrm{ab}}$ & 0.044 \\
GR & $3.6 \pm 0.4^{\mathrm{a}}$ & $3.2 \pm 0.4^{\mathrm{a}}$ & $2.4 \pm 0.2^{\mathrm{a}}$ & $3.1 \pm 0.3^{\mathrm{a}}$ & 0.380 \\
GPX & $5839.0 \pm 1020.8^{\mathrm{a}}$ & $5997.9 \pm 659.0^{\mathrm{ab}}$ & $9516.6 \pm 1801.7^{\mathrm{c}}$ & $8194.9 \pm 1383.5^{\mathrm{bc}}$ & 0.025 \\
Total GST & $223.6 \pm 7.9^{\mathrm{a}}$ & $220.6 \pm 7.7^{\mathrm{a}}$ & $227.3 \pm 6.7^{\mathrm{a}}$ & $230.9 \pm 8.3^{\mathrm{a}}$ & 0.454 \\
Total SOD & $3304.8 \pm 179.0^{\mathrm{a}}$ & $3320.6 \pm 67.8^{\mathrm{a}}$ & $3227.8 \pm 71.3^{\mathrm{a}}$ & $3378.6 \pm 199.5^{\mathrm{a}}$ & 0.566 \\
SOD1 & $2236.3 \pm 182.3^{\mathrm{a}}$ & $2356.1 \pm 67.3^{\mathrm{a}}$ & $2169.1 \pm 137.3^{\mathrm{a}}$ & $2238.2 \pm 258.8^{\mathrm{a}}$ & 0.776 \\
SOD2 & $1068.5 \pm 73.3^{\mathrm{a}}$ & $970.3 \pm 49.9^{\mathrm{a}}$ & $1058.6 \pm 82.5^{\mathrm{a}}$ & $1140.4 \pm 61.4^{\mathrm{a}}$ & 0.112 \\
\hline
\end{tabular}

1 


\section{Table 2 (on next page)}

Delta body and liver weight and biochemical parameters in plasma obtained from each experimental group.

Data are represented as mean \pm S.E.M. ( $n=3-7$ / group). Different letters mean significative differences (ANOVA, $p \leq 0.05$ ). "Delta weight was calculated as the rat's body weight on the fifth day minus its body weight on the first day of the experiment and is shown in absolute value. 'Liver value was calculated as the rat's liver weight $(\mathrm{g})$ per $100 \mathrm{~g}$ of rat's body weight on the fifth day of the experiment. AST: aspartate aminotransferase; ALT: alanine aminotransferase; BUN: blood urea nitrogen; $\mathrm{S}-\mathrm{P}-$, rats neither exposed to stress nor with piracetam treatment; $\mathrm{S}-\mathrm{P}+$, rats not exposed to stress but treated with piracetam; $\mathrm{S}+\mathrm{P}-$, rats exposed to stress without piracetam treatment; $\mathrm{S}+\mathrm{P}+$, rats exposed to stress and treated with piracetam. 


\begin{tabular}{lccccc}
\hline & S-P- & S-P+ & S+P- & S+P+ & p-value \\
\hline Delta weight (g) & $11.74 \pm 2.13^{\mathrm{a}}$ & $8.68 \pm 3.94^{\mathrm{a}}$ & $10.54 \pm 3.97^{\mathrm{a}}$ & $15.20 \pm 7.12^{\mathrm{a}}$ & 0.382 \\
Liver (g/100 g body weight) ${ }^{\dagger}$ & $4.25 \pm 0.15^{\mathrm{a}}$ & $4.21 \pm 0.19^{\mathrm{a}}$ & $4.40 \pm 0.23^{\mathrm{a}}$ & $4.04 \pm 0.18^{\mathrm{a}}$ & 0.501 \\
Glucose (mmol/L) & $14.49 \pm 0.92^{\mathrm{b}}$ & $11.52 \pm 1.57^{\mathrm{a}}$ & $12.66 \pm 1.81^{\mathrm{a}}$ & $14.96 \pm 1.35^{\mathrm{b}}$ & 0.012 \\
Triglycerides (mmol/L) & $1.19 \pm 0.11^{\mathrm{a}}$ & $1.41 \pm 0.40^{\mathrm{a}}$ & $0.86 \pm 0.04^{\mathrm{a}}$ & $1.39 \pm 0.27^{\mathrm{a}}$ & 0.522 \\
Cholesterol (mmol/L) & $1.68 \pm 0.10^{\mathrm{a}}$ & $1.69 \pm 0.09^{\mathrm{a}}$ & $1.64 \pm 0.07^{\mathrm{a}}$ & $1.68 \pm 0.14^{\mathrm{a}}$ & 0.983 \\
Liver injury & & & & \\
Direct bilirubin (mmol/L) & $0.46 \pm 0.11^{\mathrm{a}}$ & $0.37 \pm 0.09^{\mathrm{a}}$ & $0.32 \pm 0.08^{\mathrm{a}}$ & $0.38 \pm 0.09^{\mathrm{a}}$ & 0.514 \\
Indirect bilirubin (mmol/L) & $1.27 \pm 0.24^{\mathrm{a}}$ & $0.89 \pm 0.13^{\mathrm{a}}$ & $0.99 \pm 0.36^{\mathrm{a}}$ & $0.67 \pm 0.30^{\mathrm{a}}$ & 0.120 \\
Total bilirubin (mmol/L) & $1.73 \pm 0.25^{\mathrm{a}}$ & $1.40 \pm 0.12^{\mathrm{a}}$ & $1.33 \pm 0.23^{\mathrm{a}}$ & $1.22 \pm 0.38^{\mathrm{a}}$ & 0.067 \\
AST (IU/L) & $50.40 \pm 2.24^{\mathrm{a}}$ & $51.60 \pm 3.74^{\mathrm{a}}$ & $55.72 \pm 8.29^{\mathrm{a}}$ & $54.50 \pm 3.71^{\mathrm{a}}$ & 0.683 \\
ALT (IU/L) & $34.17 \pm 2.73^{\mathrm{a}}$ & $33.28 \pm 1.51^{\mathrm{a}}$ & $34.62 \pm 3.40^{\mathrm{a}}$ & $35.35 \pm 2.92^{\mathrm{a}}$ & 0.965 \\
Albumin (g/L) & $36.47 \pm 0.65^{\mathrm{a}}$ & $36.39 \pm 0.54^{\mathrm{a}}$ & $35.74 \pm 1.15^{\mathrm{a}}$ & $35.94 \pm 1.04^{\mathrm{a}}$ & 0.714 \\
Total protein (g/L) & $65.17 \pm 3.19^{\mathrm{a}}$ & $66.91 \pm 3.42^{\mathrm{a}}$ & $64.17 \pm 3.43^{\mathrm{a}}$ & $66.27 \pm 4.12^{\mathrm{a}}$ & 0.848 \\
Kidney function & & & & & \\
Urea (mmol/L) & $5.46 \pm 0.33^{\mathrm{ab}}$ & $5.45 \pm 0.42^{\mathrm{ab}}$ & $5.65 \pm 0.35^{\mathrm{b}}$ & $4.68 \pm 0.28^{\mathrm{a}}$ & 0.025 \\
Creatinine (mmol/L) & $24.71 \pm 1.38^{\mathrm{a}}$ & $20.02 \pm 2.07^{\mathrm{a}}$ & $22.88 \pm 2.40^{\mathrm{a}}$ & $22.37 \pm 2.06^{\mathrm{a}}$ & 0.178 \\
BUN (mmol/L) & $2.59 \pm 0.14^{\mathrm{b}}$ & $2.52 \pm 0.20^{\mathrm{ab}}$ & $2.64 \pm 0.17^{\mathrm{c}}$ & $2.19 \pm 0.13^{\mathrm{a}}$ & 0.025 \\
\hline
\end{tabular}

